\title{
An Inflow-Driven Valve System for Pulse Detonation Engines
}

\author{
Ken Matsuoka ${ }^{1}$, Jun Yageta $^{2}$, Tatsuya Nakamichi ${ }^{2}$, Jiro Kasahara ${ }^{3}$ \\ University of Tsukuba, Tsukuba, 305-8573, Japan \\ Takashi Yajima $^{4}$ \\ IHI Aerospace Engineering, Tomioka, 370-2307, Japan \\ and \\ Takayuki Kojima ${ }^{5}$ \\ JAXA Aerospace Research and Development Directorate, Chofu, 182-8522, Japan \\ Submitted on September 28, 2009 \\ Presented as Paper AIAA-2009-5313 at the 45 ${ }^{\text {th }}$ AIAA/ASME/SAE/ASEE Joint Propulsion Conference and Exhibit, \\ Denver, CO, 2-5 August 2009
}

\begin{abstract}
We proposed a new valve system for a pulse detonation engine (PDE) that uses a simple inflow-driven piston-interrupting valve (IDV). This valve can generate an intermittent flow by using gas enthalpy, so no power source or control unit is necessary. The mass flow per valve unit mass is comparatively large, the thrust change with changing supply pressure is very responsive, and the inflow supply pressure range for stable operation is wide. In a mass flow rate measurement experiment using a single-piston IDV, the operation frequency and mass flow rate were predictable. In a thrust measurement experiment with a pulse detonation rocket engine (PDRE) using a three-piston IDV, we confirmed the PDRE's stable operation over a wide range of supply pressure and measured the time-averaged thrust. The maximum time-averaged thrust of $22.6 \mathrm{~N}$ was achieved at a fuel (ethylene) supply pressure of 0.95 MPa and an oxygen supply pressure of 1.9 MPa. The maximum specific impulse of

\footnotetext{
${ }^{1}$ Graduate Student, Department of Engineering Mechanics and Energy, 1-1-1 Tennodai, Tsukuba, Student Member AIAA.

2 Graduate Student, Department of Engineering Mechanics and Energy, 1-1-1 Tennodai, Tsukuba.

3 Associate Professor, Department of Engineering Mechanics and Energy, 1-1-1 Tennodai, Tsukuba, Senior Member AIAA.

${ }^{4}$ Manager, Development Section No.1, 900 Fujiki, Tomioka, Development Department.

${ }^{5}$ Researcher, Aerospace Research and Development Directorate, 7-44-1Jindaijihigashimachi, Chofu, Member AIAA.
} 
Pre-print ver. (Matsuoka, Yageta, Nakamichi, Kasahara, Yajima, Kojima, JOURNAL OF PROPULSION AND POWER Vol. 27, No. 3, May-June 2011)

279 sec was achieved at an ethylene supply pressure of $0.8 \mathrm{MPa}$ and an oxygen supply pressure of 1.6 MPa.

\section{Nomenclature}

$$
\begin{aligned}
& A=\text { cross section } \\
& e \quad=\quad \text { rebound coefficient } \\
& F \quad=\quad \text { time-averaged thrust } \\
& f \quad=\quad \text { operation frequency } \\
& g=\text { gravitational acceleration } \\
& I \quad=\quad \text { impulse } \\
& I_{\mathrm{sp}} \quad=\quad \text { specific impulse } \\
& k=\text { spring constant } \\
& M \quad=\quad \text { molar mass } \\
& m=\text { mass } \\
& \dot{m}=\text { mass flow rate } \\
& N=\text { number of cycle } \\
& p \quad=\quad \text { absolute pressure } \\
& \mathfrak{R}=\text { universal gas constant } \\
& S=\text { spark noise } \\
& T=\text { absolute temperature } \\
& t=\text { time } \\
& V \quad=\quad \text { volume } \\
& w \quad=\quad \text { mechanical work } \\
& x=\text { displacement } \\
& \dot{x}=\text { velocity } \\
& \ddot{x}=\text { acceleration }
\end{aligned}
$$


Pre-print ver. (Matsuoka, Yageta, Nakamichi, Kasahara, Yajima, Kojima, JOURNAL OF PROPULSION AND POWER Vol. 27, No. 3, May-June 2011)

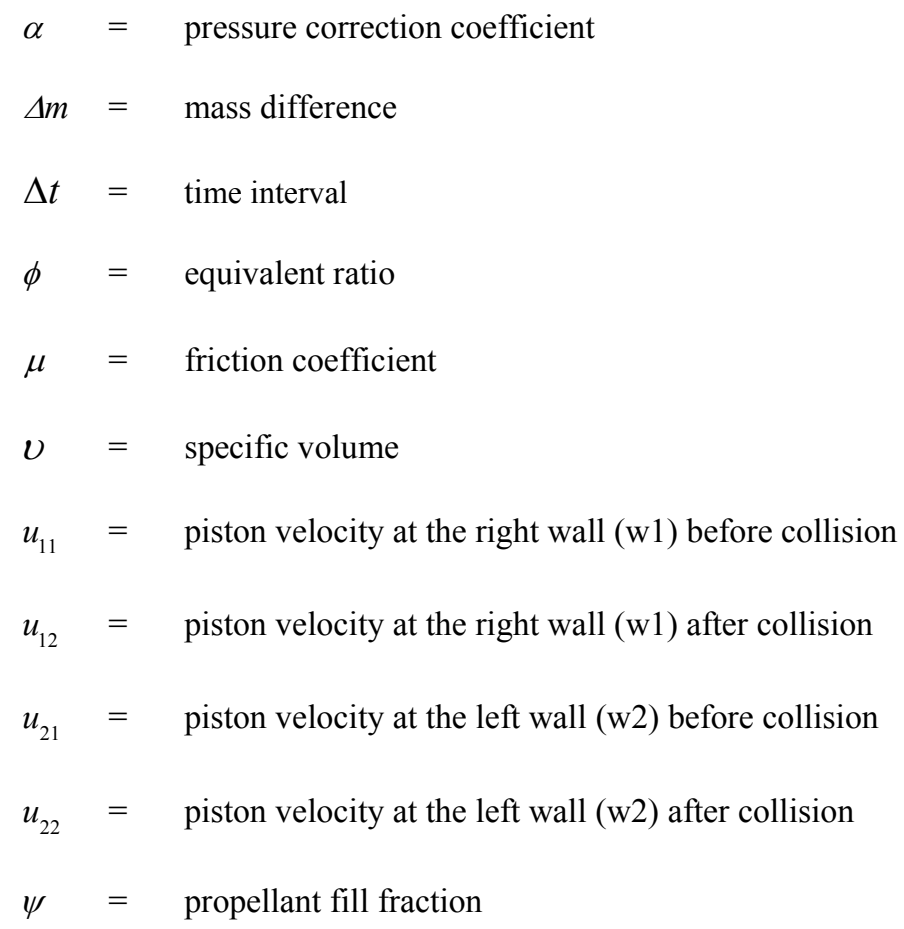

\section{Subscripts}

a $=$ ambient gas
ave $=$ average
$\mathrm{b}=$ inside of a tank
cal $=$ calculation
cr $=$ critical
cycle $=1$ cycle
exhaust
exp $=$ experiment
$\mathrm{f}=$ fuel
$\mathrm{i}=$ purge gas
ign $=$ ignition
in $=$ inside of a cylinder
$\mathrm{lc}=$ load cell


Pre-print ver. (Matsuoka, Yageta, Nakamichi, Kasahara, Yajima, Kojima, JOURNAL OF PROPULSION AND POWER Vol. 27 , No. 3, May-June 2011)

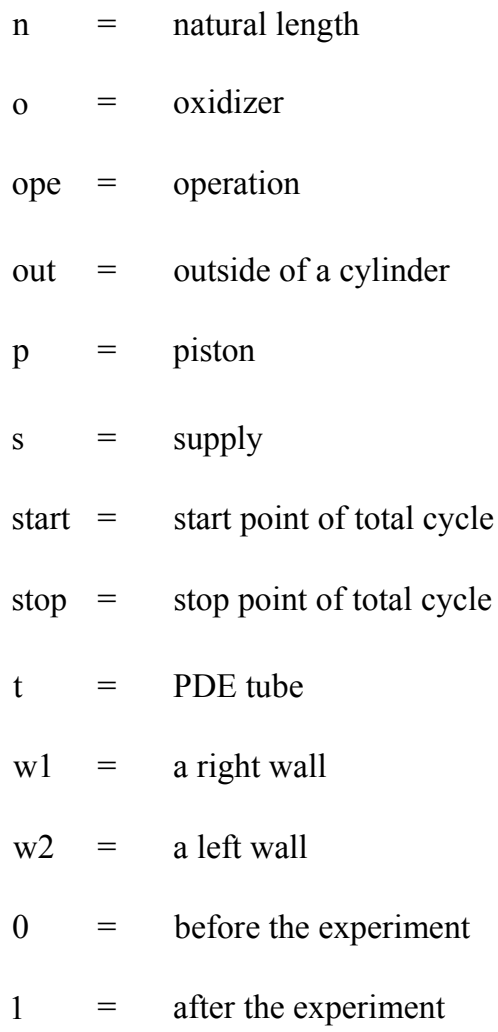

\section{Introduction}

INCE the detonation phenomenon was discovered in 1881, many fundamental studies [1, 2] and application studies of detonation waves [3-11] have been carried out. A pulse detonation engine (PDE) [12-22] is a thermal engine that generates a detonation wave intermittently and performs its mechanical work or thrust in response to high-pressure gas generated by a detonation. A PDE can obtain nearly constant thrust and perform mechanical work by the generation of a high-frequency detonation wave. PDEs are classified based on whether they are air-breathing PDEs [23-29] or pulse detonation rocket engines (PDREs) [30-37] and based on whether they include a turbine, as pure PDEs, or not, as pulse detonation turbine engines (PDTEs) [38, 39]. According to Endo et al. [39], the thermal efficiency of the PDE cycle is higher than that of constant-volume combustion (Humphrey cycle) or constant-pressure combustion (Brayton cycle). With a stoichiometric hydrogen-air mixture, the thermal efficiency is $28 \%$ if the initial compression ratio is one. With a higher compression ratio, the thermal efficiency becomes higher. In a PDE, the propellant gas is compressed and combusted by a shock wave, and thus a PDE can generate high pressure without a compression mechanism such as compressors and pistons. One goal in the development of supply 
Pre-print ver. (Matsuoka, Yageta, Nakamichi, Kasahara, Yajima, Kojima, JOURNAL OF PROPULSION AND POWER Vol. 27, No. 3, May-June 2011)

valve systems is to determine how to supply the propellant intermittently while maintaining the simplified structure of a PDE. Valve technology and detonation initiation methods are core PDE technologies in the practical realization of a PDE. Many studies of PDE valves have been reported [32, 40-45]. In particular, a valve system is needed that can achieve a large enough mass flow rate per valve unit to obtain a high thrust-weight ratio.

Figure 1 shows the schematic diagram of a valve system. The valve is composed of four main parts: an inflow blocker, a drive power that drives the blocker, an energy source that generates the drive power, and a control unit that controls the energy source (see Table 1). The valves for a PDE are classified into two broad groups, rotary valves [40] and reciprocal valves. The rotor plate of a rotary valve is driven by a motor (electromagnetic power), and the mass flow rate per valve unit mass is large because of the rotary movement. Such a valve can operate at high frequency by increasing the number of rotations of the valve. However, in the case of a large inertia moment around the axis, the response in thrust change is slow. Moreover, gas leaking occurs on the rotation sliding surface.

Reciprocal valves can be classified as piston-interrupting valves and gas-interrupting valves based on the kind of inflow blocker. If the piston mass of the piston-interrupting valve is light, the response in thrust change is quick, but the mass flow per valve unit mass is small because of the coil needed to drive the piston. A gas-interrupting valve (valveless) interrupts the inflow by means of the pressure gradient between the inflow and outflow generated by a detonation wave. Since this valve has no movable parts, the mass flow rate per valve unit mass is quite high, but the region of inflow for stable operation is narrow, because the inflow is restricted by the outflow. Each of these valve types has advantages and disadvantages, and there are technical problems when applying them to PDEs.

Recently, a PDE concept was proposed by Golub et al $[42,43]$ in which the piston can reciprocate in response to spring force and enthalpy generated by the detonation wave, thereby supplying propellant to a combustor intermittently. This system is very simple, because no power source or controller unit is necessary, but it is difficult to operate over a wide range of supply pressure, because the supply pressure depends on the outflow conditions, such as the presence of a gas-interrupting valve.

Yamaguchi et al. $[43,44]$ proposed an inflow-driven valve (IDV) in which inflow is used to interrupt the piston. This valve does not require an energy source inside the valve system, so the mass flow rate per valve unit mass is comparatively large and the region of inflow for stable operation is wide. Since this valve can change the thrust by simply changing the mass flow rate of the inflow, the response of the thrust change is very good. Yamaguchi et al. [41] carried out a combustion experiment with a two-piston IDV and found that the region of inflow for stable 
Pre-print ver. (Matsuoka, Yageta, Nakamichi, Kasahara, Yajima, Kojima, JOURNAL OF PROPULSION AND POWER Vol. 27, No. 3, May-June 2011)

operation was restricted, because their two-piston IDV did not have a piston to handle the purge gas. The authors did not measure the thrust in their experiment.

It is difficult to consider a supply valve system separately from the combustion chamber, because there are interaction problems of detonation initiation (purge, mixing, and ignition) and energy loss due to dissipation. Even if we can independently establish a supply valve system, we cannot confirm whether detonation can occur in the combustor until we carry out the thrust measurement by the total system. In the case of PDREs, we must concentrate on specific impulse performance and aim for a lightweight, simple design. With these goals in mind, we established a PDRE system with a three-piston IDV that included a piston for the purge gas. We performed thrust measurement using this PDRE system and evaluated the stable operation and performance of the thrust.

\section{Inflow-Driven Valve}

\section{A. IDV Principle}

An IDV [41] is composed of three main parts: a piston, a cylinder, and a spring. Figure 2 shows the operation conceptual diagram of an IDV, and Fig. 3 shows the ideal and actual operation cycles of an IDV as an $x-p$ diagram.

When the piston position is at $\mathrm{i}$ in Fig. 2 (also $\mathrm{i}$ in Fig. 3), propellant gas of supply pressure $p_{\mathrm{s}}$ is supplied from a tank into the cylinder and pushes the piston. The pressure difference $p_{\mathrm{s}}-p_{\mathrm{a}}$ between the supply pressure, $p_{\mathrm{s}}$, and the ambient pressure of the valve (generally atmospheric pressure), $p_{\mathrm{a}}$, is generated, and the piston begins to move in the positive direction of $x_{\mathrm{p}}$ in Fig. 2 ( $\mathrm{i} \rightarrow \mathrm{ii}$ ). In Fig. 3, the solid line shows the ideal operation cycle, and the dashed line shows the actual operation cycle.

In the ideal operation cycle, the cylinder volume is significantly larger than the change of cylinder volume caused by moving the piston, and the supply pressure is constant while the piston displacement is in $x_{\mathrm{p}} \leq x_{\mathrm{e}}$. The exhaust process in $x_{\mathrm{p}}=x_{\mathrm{e}}$ and supply process in $x_{\mathrm{p}}=x_{\mathrm{s}}$ are carried out momentarily. When the piston reaches exhaust position $x_{\mathrm{e}}$, the propellant in the cylinder is exhausted and injected into the combustor (iii).

After exhaustion, the piston is moved to position $x_{\mathrm{w} 1}$ by inertia force. The piston rebounds at the right wall of the cylinder (iv). Next, the spring pushes the piston in the negative direction of $x_{\mathrm{p}}$. The piston passes through the 
Pre-print ver. (Matsuoka, Yageta, Nakamichi, Kasahara, Yajima, Kojima, JOURNAL OF PROPULSION AND POWER Vol. 27, No. 3, May-June 2011)

supply position, $x_{\mathrm{s}}(\mathrm{v})$, and the propellant is supplied to the cylinder again (i). The internal pressure of the cylinder rises, and the piston velocity decreases. After that, the piston reaches the left wall of the cylinder, $x_{\mathrm{w} 2}$ (vi), and the piston returns to position $x_{\mathrm{s}}$ (i). The piston repeats the following cycle: $\mathrm{i}\left(\dot{x}_{\mathrm{p}}>0\right) \rightarrow$ ii $\rightarrow$ iii $\left(\dot{x}_{\mathrm{p}}>0\right)$ $\rightarrow$ iv $\rightarrow$ iii $\left(\dot{x}_{\mathrm{p}}<0\right) \rightarrow \mathrm{v} \rightarrow \mathrm{i}\left(\dot{x}_{\mathrm{p}}<0\right) \rightarrow \mathrm{vi} \rightarrow \mathrm{i}\left(\dot{x}_{\mathrm{p}}>0\right)$. The operation principle of an IDV is composed of two processes. The first process is that the piston is vibrated by the supply pressure while $\mathrm{i}\left(\dot{x}_{\mathrm{p}}<0\right) \rightarrow$ vi $\rightarrow \mathrm{i}$ $\left(\dot{x}_{\mathrm{p}}>0\right) \rightarrow$ ii. The second process is free oscillation dominated by the spring force and piston mass while iii $\left(\dot{x}_{\mathrm{p}}>0\right) \rightarrow$ iv $\rightarrow$ iii $\left(\dot{x}_{\mathrm{p}}<0\right) \rightarrow$ v. By repeating this cycle, the IDV can perform the mechanical work based on gas enthalpy and generate an intermittent flow.

\section{B. IDV Mechanical Model}

Figure 4 shows a dynamic model of an IDV. The piston mass is $m_{\mathrm{p}}$, the natural length of the spring is $x_{\mathrm{n}}$, and the spring constant is $k$. We considered the three forces acting on the piston: the spring force, $-k\left(x_{\mathrm{p}}-x_{\mathrm{n}}\right)$, the frictional force in proportion to the piston velocity, $\mu \dot{x}_{\mathrm{p}}$ ( $\mu$ is the coefficient of friction), and the force generated from the difference between the inside and outside pressure of the valve, $A_{\mathrm{p}}\left(p_{\mathrm{in}}-p_{\text {out }}\right)$, where $A_{\mathrm{p}}$ is the piston cross-section area, $p_{\text {in }}$ is the inside pressure of the cylinder, and $p_{\text {out }}$ is the outside pressure of the cylinder (the outside pressure $p_{\text {out }}$ is generally the atmospheric pressure $p_{\mathrm{a}}$ ).

The piston begins to move from the initial state $\left(x_{\mathrm{n}}, p_{\mathrm{s}}\right)$. When it reaches $x_{\mathrm{p}}=x_{\mathrm{e}}$, the inside pressure becomes $p_{\text {in }}=p_{\mathrm{a}}$, and then inertia causes the piston to continue to move in the positive direction of $x_{\mathrm{p}}$. In position $x_{\mathrm{p}}>x_{\mathrm{e}}$, the piston velocity decreases because the inside pressure is $p_{\mathrm{in}}=p_{\mathrm{a}}$. If the piston reaches the right wall, $x_{\mathrm{w} 1}$, it rebounds. The piston velocity at the right wall (w1) before collision is $u_{11}$ and after collision is $u_{12}$. The rebound coefficient is expressed as $\mathrm{e}_{\mathrm{w} 1}=-u_{12} / u_{11}$.

While inside pressure is maintained at $p_{\mathrm{in}}=p_{\mathrm{a}}$, the piston displacement decreases to $x_{\mathrm{p}}=x_{\mathrm{s}}$. The inside pressure rises to supply pressure $p_{\text {in }}=p_{\mathrm{s}}$ again at $x_{\mathrm{p}}=x_{\mathrm{s}}$. Next, the piston moves in the negative direction of $x_{\mathrm{p}}$ 
Pre-print ver. (Matsuoka, Yageta, Nakamichi, Kasahara, Yajima, Kojima, JOURNAL OF PROPULSION AND POWER Vol. 27, No. 3, May-June 2011)

while the inside pressure is maintained at $p_{\mathrm{in}}=p_{\mathrm{s}}$. In some situations, the piston reaches the left wall, $x_{\mathrm{w} 2}$, and the piston rebounds. In this case the piston velocity at the left wall (w2) before collision is $u_{21}$ and after collision is $u_{22}$. The rebound coefficient is expressed as $\mathrm{e}_{\mathrm{w} 2}=-u_{22} / u_{21}$. Finally, the piston displacement increases, and the following cycle starts. The motion equation of the piston is given as follows:

$$
m_{\mathrm{p}} \ddot{x}=-k\left(x_{\mathrm{p}}-x_{\mathrm{n}}\right)-\mu \dot{x}_{\mathrm{p}}+A_{\mathrm{p}}\left(p_{\text {in }}-p_{\text {out }}\right)
$$

This mechanical model assumes the ideal operation cycle. The natural frequency is $\sqrt{\left(k / m_{\mathrm{p}}\right)} / 2 \pi$ and the resonance frequency of forced oscillation of this spring-damper-valve system is $\sqrt{\left(k / m_{\mathrm{p}}\right)\left(1-2 \zeta^{2}\right)} / 2 \pi$, where $\zeta\left(=\mu / 2 \sqrt{m_{\mathrm{p}} k}\right)$ is the damping coefficient. Under the conditions of the calculation, the resonance frequency was nearly equal to the natural frequency because square of the damping coefficient, $\zeta^{2}$, was negligibly-small. Moreover, the piston collides with the side walls, and the operation frequency is much higher than the natural frequency. As shown in Fig. 10, the operation frequency increased in proportion to the supply pressure and the maximum operation frequency was about twice the natural operation frequency.

In this case the inside pressure of cylinder $p_{\text {in }}$ in the first process is given as follows:

$$
p_{\text {in }}=\alpha p_{\mathrm{s}}
$$

In the experiment, a finite time was necessary to supply and exhaust. With increase the operation frequency, open time for the supply and exhaust ports decrease. However, in this model, the supply and exhaust processes are carried out discontinuously. Decrease of the operation frequency due to these actual processes is not considered in this model. Therefore, we assumed that the calculation frequency $f_{\text {cal }}$ was identical to the experimental frequency $f_{\text {exp }}$ by using a pressure correction coefficient $\alpha$. The inside pressure of cylinder $p_{\text {in }}$ in the second process is given as follows:

$$
p_{\text {in }}=p_{\text {out }}
$$

We can obtain the piston movement by solving this equation.

\section{IDV Mass Flow Rate}


Pre-print ver. (Matsuoka, Yageta, Nakamichi, Kasahara, Yajima, Kojima, JOURNAL OF PROPULSION AND POWER Vol. 27, No. 3, May-June 2011)

The mass flow per 1 cycle of an IDV was obtained as the mass of the gas put into the cylinder. When the cylinder volume is $V_{\mathrm{c}}$, the supply pressure is $p_{\mathrm{s}}$ and the temperature of the gas is $T_{\text {ave }}$, which is constant. The mass flow rate per 1 cycle is obtained from the following ideal gas equation:

$$
m_{\text {cal, cycle }}=\frac{M V_{\text {in }}\left(p_{\mathrm{s}}-p_{\mathrm{a}}\right)}{\mathfrak{R} T_{\text {ave }}}
$$

where $M$ is the molar mass, $\mathfrak{R}$ is the universal gas constant, and $T_{\text {ave }}$ is the average gas temperature in the tank between before and after the operation. The mass flow rate is given as follows:

$$
\dot{m}_{\text {cal }}=m_{\text {cal }, \text { cycle }} f_{\text {cal }}
$$

where $f_{\text {cal }}$ is the operation frequency, which was obtained from the trajectory of the piston displacement which was obtained by solving the Eq. (1).

\section{A Three-Piston IDV System for a PDRE}

A three-piston IDV has a piston for each type of gas, that is, oxidizer, fuel, and purge gas (see Fig. 5). The propellant (oxidizer and fuel) and purge gas must be exhausted to the PDE tube on different schedules. Figure 6 shows the open-close operation of each port and the on-off operation of the igniter. Since each piston is fixed by a fixed board, the three pistons can be synchronized. As shown in Fig. 5, each cylinder has a supply port and an exhaust port. Although all supply port positions in direction $x_{\mathrm{p}}$ are the same, the exhaust port positions in direction $x_{\mathrm{p}}$ for propellant or purge gas are different.

Initially, all gas is supplied to the IDV at the same time in state I of Fig. $5\left(x_{\mathrm{p}}=x_{\mathrm{s}}\right.$, state I of Fig. 6). Then the piston begins to move in the positive direction of $x_{\mathrm{p}}$ due to the generated pressure difference. The purge gas is first exhausted from the IDV and injected into the combustor in state II of Fig. 5 ( $x_{\mathrm{p}}=x_{\mathrm{e}, \mathrm{i}}$, state II of Fig. 6). Since the oxidizer and the fuel are inside the cylinder, the piston moves in the positive direction of $x_{\mathrm{p}}$. In state III $\left(x_{\mathrm{p}}=x_{\mathrm{e}, \mathrm{d}}\right.$, state II of Fig. 6), the oxygen and the fuel are exhausted from the IDV and injected into the combustor. When all gases are exhausted completely, the piston moves in the negative direction of $x_{\mathrm{p}}$ because of spring force after the 
Pre-print ver. (Matsuoka, Yageta, Nakamichi, Kasahara, Yajima, Kojima, JOURNAL OF PROPULSION AND POWER Vol. 27, No. 3, May-June 2011)

piston rebounds from the wall. While the piston moves in the negative direction of $x_{\mathrm{p}}$, the ignition is carried out in state IV, where all exhaust ports are closed $\left(x_{\mathrm{p}}=x_{\mathrm{ign}}\right.$, state IV of Fig. 6). Neither the detonation wave nor the burned gas can propagate into the cylinder from the tube attached to the PDE tube. Next, the piston position reaches state $\mathrm{V}\left(x_{\mathrm{p}}=x_{5}\right.$, state $\mathrm{V}$ of Fig. 6), where the exhaust port for the purge gas is open. If the purge gas was not exhausted completely prior to this, exhaustion is completed at this stage. Finally, the piston returns to the initial position, I, and each type of gas is supplied. Compared with a two-piston IDV [44, 45], the three-piston IDV can operate stably over a wider range of supply pressure, because purge gas is used in the driver gas.

\section{IDV Mass Flow Rate and PDRE Thrust Measurements}

\section{A. IDV Mass Flow Rate Measurement}

Figure 7 shows a schematic diagram of mass flow rate measurement, and Figure 8 shows a photograph of a single-piston IDV used for mass flow rate measurement. The piston was fixed by a metallic plate. The metallic plate moved on the rail guide, and the piston mass could be varied by putting a mass on the metallic plate. The piston had four O-rings (MISUMI, NPB) to prevent gas leaks. Table 2 shows the experimental conditions. As shown in Fig. 7, the tank (Swagelok, 304-HDF4-1GAL, 3.8 L) was attached to the supply port of the IDV. A pressure gauge (Keller, PAA-23) and thermocouple (KEYENCE, TF-C11) were installed in the tank. The tank was filled with nitrogen gas, and the IDV operated while the nitrogen gas was exhausted from the IDV. We measured the mass flow per 1 cycle, $m_{\text {exp, cycle }}$, passing through the IDV based on the changed state of the tank. The gas was assumed to be perfect gas.

The mass flow per 1 cycle was computed as follows:

$$
m_{\text {exp, cycle }}=\frac{M V_{\mathrm{b}}}{\mathfrak{R} T_{\mathrm{ave}}} \frac{\Delta p}{N}
$$

where $\Delta p$ is the pressure difference in the tank, $V_{\mathrm{b}}$ is the inner volume of the tank, and $N$ is the number of the cycle. We obtained the average mass flow as $N=10$. The mass flow rate $\dot{m}_{\exp }$ is expressed as follows:

$$
\dot{m}_{\text {exp }}=m_{\text {exp, cycle }} f_{\text {exp }}
$$

where $f_{\exp }$ is the operation frequency of the IDV, which was obtained from piston displacement. 
Pre-print ver. (Matsuoka, Yageta, Nakamichi, Kasahara, Yajima, Kojima, JOURNAL OF PROPULSION AND POWER Vol. 27, No. 3, May-June 2011)

\section{B. PDRE Thrust Measurement}

We evaluated the thrust performance of the PDRE system with a three-piston IDV and recorded stable operation of the IDV. Figure 9 shows a schematic diagram of the thrust measurement experiment apparatus. The three pistons were fixed by a metallic plate, the metallic plate moved on the rail guide, and the piston mass could be varied by putting a mass on the metallic plate in common with the singe-piston IDV. Each piston had four O-rings (MISUMI, NPB) to prevent gas leaks. A proximity sensor was used for ignition (KEYENCE, EV-118M). The proximity sensor sent an ignition signal, as seen in state IV of Fig. 5. Table 3 shows the experimental conditions. We used an ethylene-oxygen mixture as the propellant and helium gas as the purge gas. The supply pressure of oxygen was changed from 0.6 MPa to 1.9 MPa.

If the PDE tube was filled with purge gas without diffusion, the thickness of the purge gas per PDE tube was $13 \%$ (approximately $150 \mathrm{~mm}$ ) at a helium supply pressure of $2.6 \mathrm{MPa}$. This supply pressure was decided empirically so that the mechanism could operate with stability. In shot numbers $1,4,7,8,11$, and 14 , the thrust measurement was carried out three times to ensure repeatability of the experiment, and the average values were plotted. As shown in Fig. 9, a pressure gauge (Keller, PAA-23) and a thermocouple (KEYENCE, TF-C11) were installed between the tank and the pressure regulator to measure the gas mass in the tank. The mass flow rate was obtained from the change in state in the tank. The mass difference, $\Delta m_{\text {exp }}$, between before and after the operation was computed as follows:

$$
\Delta m_{\exp }=m_{\mathrm{exp}, 0}-m_{\exp , 1}=\left(\frac{V_{\mathrm{b}}}{v_{\mathrm{b}, 0}}-\frac{V_{\mathrm{b}}}{v_{\mathrm{b}, 1}}\right)
$$

where $V_{\mathrm{b}}$ is the inner volume of the tank, and the inner volume for oxygen, ethylene, and helium was $47.4 \mathrm{~L}, 47.1$ $\mathrm{L}$, and $47.5 \mathrm{~L}$, respectively. $v_{\mathrm{b}}$ is the specific volume of each gas. The pressure of each gas inside the tank was 2.0 $\mathrm{MPa}$ or more. The real gas effect was considered, because the density was high and interaction between the molecules could not be neglected. Based on the state equation of van der Waals, the specific volume in Eq. (6) was obtained by solving the following equation:

$$
\left(p_{\mathrm{b}}+\frac{a}{v_{\mathrm{b}}^{2}}\right)\left(v_{\mathrm{b}}-b\right)=R T_{\mathrm{b}}
$$


Pre-print ver. (Matsuoka, Yageta, Nakamichi, Kasahara, Yajima, Kojima, JOURNAL OF PROPULSION AND POWER Vol. 27, No. 3, May-June 2011)

where $p_{\mathrm{b}}$ is the internal pressure of the tank, $T_{\mathrm{b}}$ is the internal temperature of the tank, and $a$ and $b$ were given by the following equations:

$$
a=\frac{27 R^{2} T_{\mathrm{cr}}^{2}}{64 p_{\mathrm{cr}}} \quad b=\frac{R T_{\mathrm{cr}}}{8 p_{\mathrm{cr}}}
$$

where the critical pressure, $p_{\mathrm{cr}, \mathrm{o}}$, and critical temperature, $T_{\mathrm{cr}, \mathrm{o}}$, of oxygen are $5.04 \mathrm{MPa}$ and $154.6 \mathrm{~K}$, the critical pressure, $p_{\text {cr,f }}$, and critical temperature, $T_{\text {cr, }}$, of ethylene are $5.03 \mathrm{MPa}$ and $282.4 \mathrm{~K}$, and the critical pressure, $p_{\mathrm{cr}, \mathrm{i}}$, and critical temperature, $T_{\mathrm{cr}, \mathrm{i}}$, of helium are $0.23 \mathrm{MPa}$ and $5.2 \mathrm{~K}$, respectively. The mass flow rate was evaluated from the mass difference and operating time interval, as follows:

$$
\dot{m}_{\mathrm{exp}}=\frac{\Delta m_{\mathrm{exp}}}{\Delta t_{\mathrm{ope}}}
$$

where $\Delta t_{\text {ope }}$ is the operating time interval determined by solenoid valves (CKD, AB41 series). The solenoid valve was controlled by a programmable logic controller (KEYENCE, KV-700). The mass flow was small in the condition of low supply pressure (shots $1,2,8$, and 9), so the operating time interval was extended to improve measurement accuracy.

We measured the thrust by using a PDRE and a load cell. In our PDRE, a PDE tube was fixed to a rail guide. A spring $(k=9800 \mathrm{~N} / \mathrm{m})$ was attached between the PDE tube and the load cell to smooth the impulse of the detonation wave.

The total impulse, $I_{\text {exp }}$, was given as follows:

$$
I_{\exp }=\int_{t_{\text {start }}}^{t_{\text {stop }}} F_{\mathrm{lc}} d t
$$

where $t_{\text {start }}$ is the start time of the operation, and $t_{\text {stop }}$ is a point at the intersection of the base line $(0 \mathrm{~N})$ with the last negative gradient, because the load cell output did not become $0 \mathrm{~N}$ after the operation and the load cell output was different in each experiment. The time-averaged thrust, $F_{\text {exp }}$, was expressed as follows: 
Pre-print ver. (Matsuoka, Yageta, Nakamichi, Kasahara, Yajima, Kojima, JOURNAL OF PROPULSION AND POWER Vol. 27, No. 3, May-June 2011)

$$
F_{\text {exp }}=\frac{I_{\text {exp }}}{t_{\text {stop }}-t_{\text {start }}}
$$

The experimental specific impulse, $I_{\text {sp exp }}$, was obtained using the following equation:

$$
I_{\mathrm{sp}, \mathrm{exp}}=\frac{F_{\text {exp }}}{g\left(\dot{m}_{\mathrm{exp}, \mathrm{o}}+\dot{m}_{\mathrm{exp}, \mathrm{f}}\right)}
$$

From the measured mass flow rate, $\dot{m}_{\text {exp }}$, the operation frequency, $f_{\text {exp }}$, the volume of PDE tube, $V_{\mathrm{t}}$, and the gaseous species, we calculated the specific impulse, $I_{\text {sp,cal }}$, and the calculated thrust, $F_{\text {cal }}$. The specific impulse can be a function of the number of cycles, $N$, the equivalent ratio, $\phi$, and the propellant fill fraction in combustor, $\psi$, as follows:

$$
I_{\mathrm{sp}}(\phi, \psi, N)
$$

From the equation of Kasahara et al. [23], specific impulses of the first cycle, $I_{\mathrm{sp}}(\phi, \psi, 1)$, and the second and higher cycles, $I_{\mathrm{sp}}(\phi, \psi, 2)$, are given in the following equations:

$$
\begin{aligned}
& I_{\mathrm{sp}}(\phi, \psi, 1)=I_{\mathrm{sp}}(1,1,1) \sqrt{1+\frac{f_{\text {exp }} V_{\mathrm{t}} \frac{p_{\mathrm{a}}}{T_{\mathrm{a}}}-\dot{m}_{\text {exp }, \mathrm{o}} \frac{\mathfrak{R}}{M_{\mathrm{o}}}-\dot{m}_{\text {exp }, \mathrm{f}} \frac{\Re}{M_{\mathrm{f}}}}{\mathfrak{R}\left(\dot{m}_{\text {exp }, \mathrm{o}}+\dot{m}_{\text {exp } \mathrm{f}}\right) / M_{\mathrm{a}}}} \\
& I_{\mathrm{sp}}(\phi, \psi, 2)=I_{\mathrm{sp}}(1,1,2) \sqrt{1+\frac{f_{\text {exp }} V_{\mathrm{t}} \frac{p_{\mathrm{a}}}{T_{\mathrm{a}}}-\dot{m}_{\text {exp }, \mathrm{o}} \frac{\mathfrak{R}}{M_{\mathrm{o}}}-\dot{m}_{\text {exp }, \mathrm{f}} \frac{\Re}{M_{\mathrm{f}}}}{\mathfrak{R}\left(\dot{m}_{\text {exp }, \mathrm{o}}+\dot{m}_{\text {exp }, \mathrm{f}}\right) / M_{\mathrm{i}}}}
\end{aligned}
$$

In the first cycle, the inert gas was air $\left(R_{\mathrm{a}}=287.1 \mathrm{~J} /(\mathrm{kg} \mathrm{K})\right)$. In the second and higher cycles, the inert gas was helium $\left(R_{\mathrm{i}}=2078 \mathrm{~J} /(\mathrm{kg} \mathrm{K})\right)$. In the case of ethylene-oxygen propellant, $I_{\mathrm{sp}}(1,1)=171.2 \mathrm{sec}[13]$ and $D(1)=2375.8$ $\mathrm{m} / \mathrm{sec}[46]$. The average specific impulse, $I_{\mathrm{sp}, \text { cal }}$, was determined using the following equation:

$$
I_{\mathrm{sp}, \mathrm{cal}}=\frac{\left(f_{\mathrm{exp}}-1\right) I_{\mathrm{sp}}(\phi, \psi, 2)+I_{\mathrm{sp}}(\phi, \psi, 1)}{f_{\exp }}
$$


Pre-print ver. (Matsuoka, Yageta, Nakamichi, Kasahara, Yajima, Kojima, JOURNAL OF PROPULSION AND POWER Vol. 27, No. 3, May-June 2011)

The thrust can be obtained from the specific impulse, so that $F_{\text {cal }}$ can be obtained from $\dot{m}_{\text {exp }}$, as follows:

$$
F_{\mathrm{cal}}=I_{\mathrm{sp}, \mathrm{cal}} g\left(\dot{m}_{\mathrm{exp}, \mathrm{o}}+\dot{m}_{\mathrm{exp}, \mathrm{f}}\right)
$$

The propellant fill fraction $\Psi$ was defined as the propellant volume (in ambient temperature and pressure) divided by the detonation tube volume.

$$
\psi=\frac{\left(V_{\mathrm{o}, 1 \text { cycle }}+V_{\mathrm{f}, 1 \text { cycle }}\right)}{V_{t}}=\frac{T_{\mathrm{a}} \mathfrak{R}}{p_{\mathrm{a}} V_{t} f_{\exp }}\left(\frac{\dot{m}_{\mathrm{exp}, \mathrm{o}}}{M_{\mathrm{o}}}+\frac{\dot{m}_{\text {exp }, \mathrm{f}}}{M_{\mathrm{f}}}\right)
$$

We confirmed that the cycle on the $p_{\mathrm{e}, \mathrm{o}}-x_{\mathrm{p}}$ diagram $\left(p_{\mathrm{e}, \mathrm{o}}:\right.$ oxygen exhaust pressure, $x_{\mathrm{p}}$ : piston displacement) reached the limit cycle under all of the experimental conditions. Furthermore, inner areas of all of the cycles depicted on the $p_{\mathrm{e}, \mathrm{o}}-x_{\mathrm{p}}$ diagram were identical within 5\%, except the initial four cycles. As stated above, we confirmed that the limit cycle had been reached under all of the experimental conditions.

The operation frequency, which was obtained from the piston displacement except for that of the initial three cycles, was identical to the averaged operation frequency, $f_{\exp }$, within $2 \%$. We suspect the difference between the operation frequency of the limit cycle and the averaged operation frequency of the total cycle, $f_{\exp }$, was sufficiently small because the operating time interval was long enough (at least 26 cycles) compared to the transitional time interval (approximately 4 cycles).

The mass flow rate was constant under limit cycle operation, because the operation frequency and the supply pressure during limit cycle operation were constant due to the pressure regulator. We assumed that the difference between the mass flow rate of the limit cycle and the averaged mass flow of the total cycle, $\dot{m}_{\exp }$, was sufficiently small because there was a sufficient operating time interval.

The time-averaged thrust except for that of the initial four cycles was identical to the time-averaged thrust, $F_{\text {exp }}$, within $7 \%$, and we assumed that the time-averaged thrust in the transitional condition had little effect on the time-averaged thrust, $F_{\text {exp }}$.

By using the above assumptions, in this experiment, we obtained the specific impulse of the limit cycle operation by using the operation frequency, $f_{\exp }$, the mass flow rate, $\dot{m}_{\exp }$, and the time-averaged thrust, $F_{\exp }$. 
Pre-print ver. (Matsuoka, Yageta, Nakamichi, Kasahara, Yajima, Kojima, JOURNAL OF PROPULSION AND POWER Vol. 27, No. 3, May-June 2011)

\section{Results and Discussion}

\section{A. IDV Mass Flow Rate Measurement}

Figure 10 shows the relation between the experimental operation frequency, $f_{\text {exp }}$, and the calculated frequency, $f_{\text {cal }}$, in shot 1 . Figure 11 shows the relation between the experimental mass flow rate, $\dot{m}_{\text {exp }}$, and the calculated mass flow rate, $\dot{m}_{\text {cal }}$. In addition, the mass flow ratios $\left(\dot{m}_{\text {exp }} / \dot{m}_{\text {cal }}\right)$ for each of the experimental conditions are shown in Figs. 12 and 13. The operation frequency depended on the supply pressure, because the IDV used inflow enthalpy. With increasing supply pressure, the force that dominated the piston motion was changed from inertia force of the piston and restorative force of the spring to surface force by supply pressure, and the operation frequency increased. In this experiment, the mass flow rate was also increased in proportion to the operation frequency. The biggest benefit of an IDV is that operation autonomously reaches a different limit cycle when the supply mass flow is changed (the size of the orifice is changed). In fact, the mass of the outflow and the operation frequency autonomously increase while maintaining the sinusoidal operation and the valve mass when the mass flow of the inflow (inflow pressure) increases. Even if the mass flow of the inflow is small, an IDV can maintain the mass flow of the outflow, because the operation frequency can be increased by decreasing the piston mass. In our experiment, as shown in Fig. 11, the mass flow rate of $5.4 \mathrm{~g} / \mathrm{sec}$ (operation frequency: $16.7 \mathrm{~Hz}$ ) was achieved at a supply pressure ratio $\left(p_{\mathrm{s}} / p_{\mathrm{a}}\right)$ of 8.7 , a piston mass of $3.88 \mathrm{~kg}$, and a spring constant of $9800 \mathrm{~N} / \mathrm{m}$. By using the present mechanical model of the IDV, we achieved a mass flow rate of $5.6 \mathrm{~g} / \mathrm{sec}$ (operation frequency: $37.8 \mathrm{~Hz}$ ) at a supply pressure ratio of 4.3 , a piston mass of $0.3 \mathrm{~kg}$, and a spring constant of $9800 \mathrm{~N} / \mathrm{m}$.

The maximum mass flow rate of $6.1 \mathrm{~g} / \mathrm{sec}$ (maximum operation frequency $17.3 \mathrm{~Hz}$ ) was achieved under the condition of $k=9800 \mathrm{~N} / \mathrm{m}, m_{\mathrm{p}}=3.88 \mathrm{~kg}$, and $p_{\mathrm{s}}=1.0 \mathrm{MPa}$. The initial conditions for the model calculation are shown in Table 4. A comparison of the calculated frequency and the experimental frequency shows that the experimental value corresponded with the calculated value within $2 \mathrm{~Hz}$. However, the rebound coefficient and the frictional coefficient were set to $e_{\mathrm{w} 1}=0.3, e_{\mathrm{w} 2}=0.5$, and $\mu=40 \mathrm{Ns} / \mathrm{m}$, respectively, to conform to the experimental mass flow rate, and the pressure correction coefficient, $\alpha$, was between 0.6 and 1.0. In this model calculation, the internal pressure of the cylinder rises discontinuously, and the internal pressure is maintained as the supply pressure, $p_{\mathrm{s}}$, at the same time as when the supply port opens. On the other hand, opening and closing of the 
Pre-print ver. (Matsuoka, Yageta, Nakamichi, Kasahara, Yajima, Kojima, JOURNAL OF PROPULSION AND POWER Vol. 27, No. 3, May-June 2011)

valve ports was carried out for a finite length of time in the experiment. In the case of increasing the spring constant, the opening and closing time of the valve ports was shorter in proportion to the increase in operation frequency, and the experimental mass flow decreased in comparison with the model mass flow. For this reason, as shown in Fig. 12 and Fig. 13, if the spring constant increased (from $k=2940 \mathrm{~N} / \mathrm{m}$ to $k=9800 \mathrm{~N} / \mathrm{m}$ ), the pressure correction coefficient, $\alpha$, was used to conform to the flow rate $\left(\dot{m}_{\text {exp }} / \dot{m}_{\text {cal }}\right)$. In addition, the flow rate increased in proportion to the increasing supply pressure, and the flow rate was higher than 1 in the case of a piston mass of $12.8 \mathrm{~kg}$ (see Fig. 13). This was due to changing the opening and closing times of the valve ports and altering the mass flow by changing the supply pressure. For simplification, we did not consider the dependence property of the supply pressure in this model.

If the drive gas was assumed to be a perfect gas, the IDV used $10 \%(30 \mathrm{~kJ} / \mathrm{kg})$ of the kinetic energy of a gas molecule to maintain the piston motion. This energy was sufficiently small compared to the chemical energy of a combustible gas (as an example, the chemical energy of a stoichiometric ethylene-oxygen mixture is approximately $50 \mathrm{MJ} / \mathrm{kg}$ ). Velocity and temperature gradients were generated in the IDV system, and the energy dissipation was generated. The energy used to drive a piston and the dissipation are sufficiently small compared to the energy needed for thrust. In an air-breathing engine system, if the air passes through the IDV, the total pressure drop by the IDV is serious. However, in a rocket engine system, the total pressure drop in the fuel-oxidizer supply system does not much affect the thrust performance.

\section{B. PDRE Thrust Measurement}

Figure 14 shows the time history of piston displacement, $x_{\mathrm{p}}$, spark noise, $S$, and load cell output, $F_{\mathrm{lc}}$, in shot 13. Figure 15 shows one cycle of displacement, $x_{\mathrm{p}}$, the spark noise, $S$, and the exhaust pressure of oxygen and helium in shot 13 . We used piston displacement to determine the valve opening time and ignition time. Using this method, we confirmed that the PDRE system with the IDV performed stably, and a time-averaged thrust was generated.

Figure 16 shows the mass flow rate of the oxygen and ethylene with changing supply pressure under the experimental condition of $k=9010 \mathrm{~N} / \mathrm{m}$ and $m_{\mathrm{p}}=7.02 \mathrm{~kg}$. The error bars of the vertical axis are the square error in three experiments. The error bars of the horizontal axis are the square error of the accidental error and the 
Pre-print ver. (Matsuoka, Yageta, Nakamichi, Kasahara, Yajima, Kojima, JOURNAL OF PROPULSION AND POWER Vol. 27, No. 3, May-June 2011)

instrumental error of the pressure regulator for oxygen. The lines in Fig. 16 show the mass flow rates $\left(\beta \dot{m}_{\text {cal }}\right)$ which were obtained by using the calculated mass flow rate, $\dot{m}_{\text {cal }}$, of Eq. (3) and correction coefficient, $\beta$; however, the calculated operation frequency in this equation, $f_{\text {cal }}$, was replaced with the experimental operation frequency, $f_{\text {exp }}$. This mass flow rates were identical to the experiment mass flow rates when the correction coefficients, $\beta$, were 0.25 and 0.35 for ethylene and oxygen. In the thrust measurement experiment, the pressure regulators were used to supply at constant pressure. In contrast, the pressure regulators were not used in the mass flow measurement experiment. Moreover, the operation frequencies under all of the conditions of the thrust measurement experiment were comparable to the operation frequency of the mass flow measurement experiment. Therefore, this decrease of mass flow rate occurred due to not incompletely-filled of propellant, but restriction by the pressure regulators.

Figure 17 shows the time-averaged thrust, $F_{\text {exp }}$, and the calculated thrust, $F_{\text {cal }}$, under the experimental condition of $k=9010 \mathrm{~N} / \mathrm{m}$ and $m_{\mathrm{p}}=7.02 \mathrm{~kg}$, and Fig. 18 shows the experimental specific impulse, $I_{\mathrm{sp}, \exp }$, and the calculated specific impulse, $I_{\mathrm{sp}, \mathrm{cal}}$. $\mathrm{O}$ and $\boldsymbol{\Delta}$ show the experimental values, and $\bigcirc$ and $\triangle$ show the calculated values. The lines in Figs. 17 and 18 show the fitted lines obtained by using the least-squares method, and $\phi$ shows the equivalent ratios calculated from the experimental mass flow rate. The error bar of the vertical axis is the square error in three experiments. The error bar of the horizontal axis is the square error of the accidental error and the instrumental error of the pressure regulator for oxygen.

Figure 19 shows the thrust ratio $\left(F_{\text {exp }} / F_{\text {cal }}=I_{\text {sp,exp }} / I_{\text {sp,cal }}\right)$ under all experimental conditions. $\psi_{\text {plug }}$ in Fig. 19 was the propellant fill fraction in the case when propellant filled the tube to the position where the spark plug was installed (61 mm from the closed end of the PDE tube). As shown in Fig. 19, when the oxygen supply pressure was at maximum, the propellant fill fraction was approximately 0.08 and the thrust ratio was $0.8-0.9$. In this case the experimental value was lower than the calculated value. This was probably due to the lack of mixing of the propellant. In a multi-cycle experiment, the distribution of the equivalent ratio in a PDE tube is not uniform. Hence, the deflagration to detonation transition (DDT) length was longer, and the plateau pressure was lower than under ideal plateau pressure. In comparison with the experiment, a detonation wave was generated from the closed end in the calculation, and the PDRE cycle was operated in this region. When the propellant fill fraction fell to 0.05 , the thrust ratio was maintained at near $0.7-0.8$. In this region, not only the lack of mixing of the propellant but also the lack of filling with the propellant must be considered. Furthermore, at a lower propellant fill fraction, the thrust 
Pre-print ver. (Matsuoka, Yageta, Nakamichi, Kasahara, Yajima, Kojima, JOURNAL OF PROPULSION AND POWER Vol. 27, No. 3, May-June 2011)

ratio decreased rapidly. In the case of this PDRE, a detonation was not generated in less than propellant fill fraction of 0.04 due to the insufficient distance for DDT to occur.

In addition, the maximum time-averaged thrust of $22.6 \mathrm{~N}$ was achieved under the condition of a fuel (ethylene) supply gauge pressure of $0.95 \mathrm{MPa}$, an oxygen supply gauge pressure of $1.9 \mathrm{MPa}$, and a spring constant of 9010 $\mathrm{N} / \mathrm{m}$. The maximum specific impulse of $279 \mathrm{sec}$ was achieved under the condition of an ethylene supply pressure of $0.8 \mathrm{MPa}$, an oxygen supply pressure of $1.6 \mathrm{MPa}$, and a spring constant of $9010 \mathrm{~N} / \mathrm{m}$.

\section{Conclusion}

We proposed an IDV for a PDE system and presented the operation principal and the mechanical model for this system. The IDV can generate an intermittent flow by a piston driven by gas enthalpy.

We carried out a flow measurement experiment with a single-piston IDV and confirmed a maximum mass flow rate of $6.3 \mathrm{~g} / \mathrm{sec}$ (piston mass: $3.8 \mathrm{~kg}$, spring constant: $9800 \mathrm{~N} / \mathrm{m}$, supply pressure: $1.0 \mathrm{MPa}$, operation frequency: 17.3 Hz). The experimental mass flow rate was $70-120 \%$ in comparison with the calculated mass flow rate. We showed that the operation frequency and mass flow rate can be predicted. Moreover, we carried out a thrust measurement experiment of the PDRE using a three-piston IDV. Within a wide range of supply pressure, we confirmed the stable operation of this valve and measured its time-averaged thrust. We confirmed a maximum time-averaged thrust of $22.6 \mathrm{~N}$ (piston mass: $7.02 \mathrm{~kg}$, spring constant: $9010 \mathrm{~N} / \mathrm{m}$, fuel (ethylene) supply gage pressure: $0.95 \mathrm{MPa}$, oxygen supply gage pressure: $1.9 \mathrm{MPa}$, operation frequency: $10.2 \mathrm{~Hz}$ ) and a maximum specific impulse of $279 \mathrm{sec}$ (piston mass: $7.02 \mathrm{~kg}$, spring constant: $9010 \mathrm{~N} / \mathrm{m}$, fuel (ethylene) supply gage pressure: $0.8 \mathrm{MPa}$, oxygen supply gage pressure: 1.6 MPa, operation frequency: $10.2 \mathrm{~Hz}$ ).

\section{Acknowledgment}

This study was supported by Grants-in-Aid for Scientific Research, Encouragement of Young Scientists (B) 2005-2007 from the Japan Society for the Promotion of Science (JSPS).

\section{References}

[1] Lee, J. H. S., “The Detonation Phenomena” Cambridge University Press, New York, 2008.

[2] Lewis, B., and Elbe, G. V., “Combustion, Flames and Explosion of Gases,” Academic Press, New York, 1951. 
Pre-print ver. (Matsuoka, Yageta, Nakamichi, Kasahara, Yajima, Kojima, JOURNAL OF PROPULSION AND POWER Vol. 27, No. 3, May-June 2011)

[3] Nicholls, J. A., Wilkinson, H. R., and Morrison, R. B., “Intermittent Detonation as a Thrust-Producing Mechanism," Jet Propulsion, Vol. 27, No. 5, 1957, pp. 534-541.

[4] Bussing, T. R. A., and Pappas, G., "Pulse Detonation Engine Theory and Concepts," Developments in High-Speed-Vehicle Propulsion Systems, Progress in Astronautics and Aeronautics, No. 165, AIAA, 1996, pp. 421-472.

[5] Kailasanath, K., "Review of Propulsion Applications of Detonation Waves," AIAA Journal, Vol. 38, No. 9, 2000 , pp. $1698-1708$.

[6] Kasahara, J., Matsuo, A., and Endo, T., "Present Status of Pulse Detonation Engine Research” Journal of Japan Society of Fluid Mechanics, Vol. 26, No. 3, 2007, pp. 205-213.

[7] Kailasanath, K., "Recent Developments in the Research on Pulse Detonation Engines," AIAA Journal, Vol. 41, No. 2, 2003, pp. $145-159$.

[8] Bazhenova, T. V., and Golub V. V., "Use of Gas Detonation in a Controlled Frequency Mode (review)," Combustion Explosion and Shock Waves, Vol. 39, No. 4, 2003, pp. 365-381.

[9] Roy, G. D., Frolov, S. M., Borisov, A. A., and Netzer, D.W., "Pulse Detonation Propulsion: Challenges, Current Status, and Future Perspective,” Progress Energy and Combustion Science, Vol. 30, No. 6, 2004, pp. 545-672.

[10] Kailasanath, K., "Research on Pulse Detonation Combustion Systems - A Status Report," 47th AIAA Aerospace Sciences Meeting, AIAA, Orlando, FL, 2009-631, 2009.

[11] Ziton, R., and Desbordes, D., "Propulsive Performance of Pulsed Detonations," Combustion Science and Technology, Vol. 144, Sept. 1999, pp. 93-114.

[12] Endo, T., and Fujiwara, T., “A Simplified Analysis on a Pulse Detonation Engine Model," Transactions of the Japan Society for Aeronautical and Space Sciences, Vol. 44, No. 146, 2002, pp. 217-222.

[13] Endo, T., Kasahara, J., Matsuo, A., Inaba, K., Sato, S., and Fujiwara, T., "Pressure History at the Thrust Wall of a Simplified Pulse Detonation Engine," AIAA Journal, Vol. 42, No. 9, 2004, pp. 1921-1930.

[14] Endo, T., Yatsufusa, T., Taki, S., Matsuo, A., Inaba, K., and Kasahara, J., "Homogeneous-Dilution Model of Partially-Fueled Simplified Pulse Detonation Engines," Journal of Propulsion and Power, Vol. 23, No. 5, 2007, pp. $1033-1041$.

[15] Zhdan, S. A., Mitrofanov, V. V., and Sychev, A. I., "Reactive Impulse from the Explosion of a Gas Mixture in a Semiinfinite Space,” Combustion, Explosion, and Shock Wave, Vol. 30, No. 5, 1994, pp. 657-663.

[16] Cooper, M. A., "Impulse Generation by Detonation Tubes," Ph.D. thesis, California Institute of Technology, Pasadena, CA, May 2004.

[17] Cooper, M., Shepherd, J. E., and Schauer, F., "Impulse Correlation for Partially Filled Detonation Tubes," Journal of Propulsion and Power, Vol. 20, No. 5, 2004, pp. 947-950. 
Pre-print ver. (Matsuoka, Yageta, Nakamichi, Kasahara, Yajima, Kojima, JOURNAL OF PROPULSION AND POWER Vol. 27, No. 3, May-June 2011)

[18] Schauer, F., Stutrud, J., and Bradley, R., "Detonation Initiation Studies and Performance Results for Pulsed Detonation Engine,”39th Aerospace Sciences Meeting and Exhibit, AIAA, Reno, NV, 2001-1129, 2001.

[19] Sato, S., Matsuo, A., Endo, T., and Kasahara, J., "Numerical Studies on Specific Impulse of Partially Filled Pulse Detonation Rocket Engines,” Journal of Propulsion and Power, Vol. 22, No. 1, 2006, pp. 64-69.

[20] Kasahara, J., Liang, Z., Browne, S. T., and Shepherd, J. E., "Impulse Generation by an Open Shock Tube," AIAA Journal, Vol. 46, No. 7, 2008, pp. 1593-1603.

[21] Wilson, J., Sgondea, A., Paxson, D. E., and Rosenthal, B. N., "Parametric Investigation of Thrust Augmentation by Ejectors on a Pulsed Detonation Tube," Journal of Propulsion and Power, Vol. 23, No. 1, 2007, pp.108-115.

[22] Wilson, J., "Effect of Pulse Length and Ejector Radius on Unsteady Ejector Performance," Journal of Propulsion and Power, Vol. 23, No. 2, 2007, pp. 345-352.

[23] Wintenberger, V., and Shepherd, J. E., "Model for the Performance of Air-Breathing Pulse-Detonation Engines," Journal of Propulsion and Power, Vol. 22, No. 3, 2006, pp. 593-603.

[24] Wintenberger, E., Austin, J. M., Cooper, M., Jackson, S., and Shepherd, J. E., "Analytical Model for the Impulse of Single-Cycle Detonation Tube," Journal of Propulsion and Power, Vol. 19, No. 1, 2003, pp. 22-38.

[25] Cooper, M., Jackson, S., Austin, J., Wintenberger, E., and Shepherd, J. E., “Direct Experimental Impulse Measurements for Detonations and Deflagrations," Journal of Propulsion and Power, Vol. 18, No. 5, 2002, pp.

[26] Talley, D. G., and Coy E. B., "Constant Volume Limit of Pulsed Propulsion for a Constant $\gamma$. Ideal Gas," Journal of Propulsion and Power, Vol. 18, No. 2, 2002, pp. 400-406.

[27] Harris, P. G., Stowe, R. A. Ripley, R. C., and Guzik, S. M., "Pulse Detonation Engine as a Ramjet Replacement,” Journal of Propulsion and Power, Vol. 22, No. 2, 2006, pp. 462-473.

[28] Ma, F., Choi, J.-Y., and Yang, V., "Propulsive Performance of Airbreathing Pulse Detonation Engines," Journal of Propulsion and Power, Vol. 22, No. 6, 2006, pp. 1188-1203.

[29] Kojima, T., and Kobayashi, H., "Thrust Increase of Air Breathing Pulse Detonation Engine by High Supply Pressure,” Space Technology Japan, Vol. 4, 2005, pp. 35-42.

[30] Morris, C. I., "Numerical Modeling on Single-Pulse Gas Dynamics and Performance of Pulse Detonation Rocket Engines," Journal of Propulsion and Power, Vol. 21, No. 3, 2005, pp. 527-538.

[31] Fontfreyde, T., Levy, F., Dupays, J., Scherrer D., and Serre, L., "Numerical Studies of Pulse Detonation Rocket Engines," 45th AIAA/ASME/SAE/ASEE Joint Propulsion Conference and Exhibit, AIAA, Fort Lauderdale, FL, 2004-3873, 2004.

[32] Kasahara, J., Hasegawa, A., Nemoto, T., Yamaguchi H., Yajima, T., and Kojima T., "Performance Validation of a Single-Tube Pulse Detonation Rocket System,” Journal of Propulsion and Power, Vol. 25, No. 1, 2007, pp. 173-180. 
Pre-print ver. (Matsuoka, Yageta, Nakamichi, Kasahara, Yajima, Kojima, JOURNAL OF PROPULSION AND POWER Vol. 27, No. 3, May-June 2011)

[33] Kasahara, J., Hirano, M., Matsuo, A., Daimon, Y., and Endo, T., “Thrust Measurement of a Multi-Cycle Partially Filled Pulse Detonation Rocket,” Journal of Propulsion and Power, Vol. 25, No. 6, 2009, pp. 1281-1290.

[34] Hirano, M., Kasahara, J., Matsuo, A. Endo, T., and Murakami, M., "Thrust-Performance Test of Ethylene-Oxygen Single-Tube Pulse Detonation Rocket," Proceedings of the Asian Joint Conference on Propulsion and Power 2004, Seoul, South Korea, 2004, pp. 255-260.

[35] Kasahara, J., Hirano, M., Matsuo, A., Sato, S., and Endo, T., "Flight Experiments Regarding Ethylene-Oxygen Single-Tube Pulse Detonation Rocket," 40th AIAA/ASME/SAE/ASEE Joint Propulsion Conference and Exhibit, AIAA, Fort Lauderdale, FL, 2004-3918, 2004.

[36] Kasahara, J., "Pulse Detonation Rockets and Thrust Augmentation According to Partially-Filling Effect," Journal of the Combustion Society of Japan, Vol. 47, No. 140, 2005, pp. 84-89.

[37] Hasegawa, A., Nemoto, T., Yamaguchi, H., and Kasahara, J., Yajima, T., Yamamoto, F., Tanaka, H., and Kojima, T., “Thrust Demonstration of a Pulse Detonation Rocket System for Flight Test," 47th Conference on Aerospace Propulsion and Power, JSASS, Hyogo, Japan, 2007, pp. 399-404.

[38] Maeda, S., Kasahara, J., Matsuo, A., and Endo, T., “Analysis on Thermal Efficiency of Non-Compressor Type Pulse Detonation Turbine Engine," Transaction of the Japan Society for Aeronautical and Space Sciences (to be published).

[39] Endo, T., Yatsufusa, T., Taki, S., and Kasahara, J., "Thermodynamic Analysis of the Performance of a Pulse Detonation Turbine Engine," Science and Technology of Energetic Materials, Vol. 65, No. 4, 2004, pp. 103-110.

[40] Hinkey, J. B., Williams, J. T., Henderson, S. E., and Bussing, T. R. A., "Rotary-Valved, Multiple-Cycle, Pulse Detonation Engine Experimental Demonstration," 33rd AIAA/ASME/SAE/ASEE Joint Propulsion Conference and Exhibit, AIAA, Seattle, WA, 1997-2746, 1997.

[41] Baklanov, D. I,, Golovastov, S. V., Golub, V. V., Reshetnyak, R. B., Semin, N. V., and Volodin V. V., "Model of Low-Thrust Pulsed Detonation Device with Valveless Fuel Feed," 2nd European Conference for Aerospace Sciences (EUCASS), Brussels, Belgium, 2007.

[42] Golub, V. V., Golovastov, S. V., Baklanov, D. I., Volodin, V. V., Cheprunov, A. A., and Lisin, D. G. "Chamber of a Pulse Detonation Engine”, Rus. patent application, No. 2293866, Date of publication: 20 Feb. 2007.

[43] Golovastov, S. V., Baklanov, D. I., Golub, V. V., Mikushkin, A. Y., Tarasenko, I. N., and Volodin, V. V., "Vibrationlesss Pulse Detonation Engine,” 3nd European Conference for Aerospace Sciences (EUCASS), Versailles, France, 2009.

[44] Yamaguchi, H., Nemoto, T., Matsuoka, K., Yageta, J., Kasahara, J., Yajima, T., and Kojima, T., "Research on the Autonomous Driving Valve for a Pulse Detonation Engine," $51^{s t}$ Space Science and Technology Conference, JSASS, Sapporo, Japan, 2007. 
Pre-print ver. (Matsuoka, Yageta, Nakamichi, Kasahara, Yajima, Kojima, JOURNAL OF PROPULSION AND POWER Vol. 27, No. 3, May-June 2011)

[45] Yamaguchi, H., Matsuoka, K., Yageta, J., and Kasahara, J., "Study on Inflow-Driven Valves for Pulse Detonation Engines," Journal of the Japan Society for Aeronautical and Space Sciences, Vol. 57, No. 663, 2009, pp. 141-147.

[46] Tanaka, K., AISTAJAN, http://www.aist.go.jp/RIODB/ChemTherm/gas.htm 
Pre-print ver. (Matsuoka, Yageta, Nakamichi, Kasahara, Yajima, Kojima, JOURNAL OF PROPULSION AND POWER Vol. 27, No. 3, May-June 2011)

Table 1 Classification of general valve systems

\begin{tabular}{|c|c|c|c|c|c|c|c|c|c|}
\hline $\begin{array}{c}\text { Large } \\
\text { classification }\end{array}$ & $\begin{array}{c}\text { Small } \\
\text { classification }\end{array}$ & $\begin{array}{l}\text { Inflow } \\
\text { blocker }\end{array}$ & Drive power & $\begin{array}{l}\text { Energy } \\
\text { source }\end{array}$ & Control part & $\begin{array}{l}\text { Response } \\
\text { in thrust } \\
\text { change }\end{array}$ & Weight & $\begin{array}{l}\text { Pressure } \\
\text { range of } \\
\text { inflow }\end{array}$ & Reference \\
\hline Rotary valve & & $\begin{array}{l}\text { Rotor } \\
\text { plate }\end{array}$ & $\begin{array}{l}\text { Electromagn } \\
\text { etic power }\end{array}$ & $\begin{array}{c}\text { Electrical } \\
\text { energy }\end{array}$ & $\begin{array}{l}\text { Control of } \\
\text { rotary motor } \\
\text { voltage }\end{array}$ & Slow & Light & Wide & {$[40]$} \\
\hline \multirow[t]{4}{*}{$\begin{array}{l}\text { Reciprocal } \\
\text { valve }\end{array}$} & $\begin{array}{c}\text { Piston- } \\
\text { interrupting } \\
\text { valve }\end{array}$ & Piston & $\begin{array}{l}\text { Electromagn } \\
\text { etic power }\end{array}$ & $\begin{array}{l}\text { Electrical } \\
\text { energy }\end{array}$ & $\begin{array}{c}\text { Control of } \\
\text { ON-OFF of } \\
\text { electromagn } \\
\text { et }\end{array}$ & Quick & Heavy & Wide & {$[32]$} \\
\hline & $\begin{array}{c}\text { Gas- } \\
\text { interrupting } \\
\text { valve } \\
\text { (valveless) }\end{array}$ & Outflow & Pressure & $\begin{array}{l}\text { Enthalpy } \\
\text { of outflow }\end{array}$ & $\begin{array}{l}\text { Control of } \\
\text { ignition } \\
\text { timing }\end{array}$ & Quick & Very light & Narrow & {$[41]$} \\
\hline & $\begin{array}{l}\text { Outflow-driven } \\
\text { piston- } \\
\text { interrupting } \\
\text { valve }\end{array}$ & Piston & Pressure & $\begin{array}{l}\text { Enthalpy } \\
\text { of outflow }\end{array}$ & $\begin{array}{l}\text { Control of } \\
\text { ignition } \\
\text { timing }\end{array}$ & Quick & Light & Narrow & {$[42,43]$} \\
\hline & $\begin{array}{l}\text { Inflow-driven } \\
\text { piston- } \\
\text { interrupting } \\
\text { valve }\end{array}$ & Piston & Pressure & $\begin{array}{l}\text { Enthalpy } \\
\text { of inflow }\end{array}$ & $\begin{array}{l}\text { Control of } \\
\text { inflow } \\
\text { flow-rate }\end{array}$ & Quick & Light & Wide & {$[44,45]$} \\
\hline
\end{tabular}


Pre-print ver. (Matsuoka, Yageta, Nakamichi, Kasahara, Yajima, Kojima, JOURNAL OF PROPULSION AND POWER Vol. 27, No. 3, May-June 2011)

Table 2 Condition of mass flow rate measurement

\begin{tabular}{ccc}
\hline $\begin{array}{c}\text { Shot } \\
\text { number }\end{array}$ & $\begin{array}{c}\text { Spring } \\
\text { constant }\end{array}$ & $\begin{array}{c}\text { Piston } \\
\text { mass }\end{array}$ \\
\hline & $k$ & $m_{\mathrm{p}}$ \\
\hline 1 & 9800 & 3.88 \\
{$[\mathrm{~N} / \mathrm{m}]$} & 3.88 \\
3 & 4900 & 3.88 \\
4 & 2940 & 12.80 \\
5 & 9800 & 12.80 \\
6 & 4900 & 12.80 \\
\hline \hline
\end{tabular}


Pre-print ver. (Matsuoka, Yageta, Nakamichi, Kasahara, Yajima, Kojima, JOURNAL OF PROPULSION AND POWER Vol. 27, No. 3, May-June 2011)

Table 3 Condition of thrust measurement

\begin{tabular}{|c|c|c|c|c|c|c|c|}
\hline $\begin{array}{c}\text { Shot } \\
\text { number }\end{array}$ & Times & $\begin{array}{l}\text { Spring } \\
\text { constant }\end{array}$ & $\begin{array}{c}\text { Piston } \\
\text { mass }\end{array}$ & $\begin{array}{l}\text { Oxygen } \\
\text { supply } \\
\text { pressure }\end{array}$ & $\begin{array}{c}\text { Ethylene } \\
\text { supply } \\
\text { pressure }\end{array}$ & $\begin{array}{l}\text { Helium } \\
\text { supply } \\
\text { pressure }\end{array}$ & $\begin{array}{c}\text { Operating } \\
\text { duration }\end{array}$ \\
\hline & & $k$ & $m_{\mathrm{p}}$ & $p_{\mathrm{o}}$ & $p_{\mathrm{f}}$ & $p_{\mathrm{i}}$ & $\Delta \mathrm{t}_{\text {ope }}$ \\
\hline & & {$[\mathrm{N} / \mathrm{m}]$} & {$[\mathrm{kg}]$} & [MPa,gage] & [MPa,gage] & [MPa,gage] & {$[\mathrm{msec}]$} \\
\hline 1 & 3 & 6650 & 6.81 & 0.6 & 0.3 & 2.6 & 5000 \\
\hline 2 & 1 & 6650 & 6.81 & 0.8 & 0.4 & 2.6 & 5000 \\
\hline 3 & 1 & 6650 & 6.81 & 1.0 & 0.5 & 2.6 & 4000 \\
\hline 4 & 3 & 6650 & 6.81 & 1.2 & 0.6 & 2.6 & 3000 \\
\hline 5 & 1 & 6650 & 6.81 & 1.4 & 0.7 & 2.6 & 3000 \\
\hline 6 & 1 & 6650 & 6.81 & 1.6 & 0.8 & 2.6 & 3000 \\
\hline 7 & 3 & 6650 & 6.81 & 1.9 & 0.95 & 2.6 & 3000 \\
\hline 8 & 3 & 9010 & 7.02 & 0.6 & 0.3 & 2.6 & 5000 \\
\hline 9 & 1 & 9010 & 7.02 & 0.8 & 0.4 & 2.6 & 5000 \\
\hline 10 & 1 & 9010 & 7.02 & 1.0 & 0.5 & 2.6 & 3000 \\
\hline 11 & 3 & 9010 & 7.02 & 1.2 & 0.6 & 2.6 & 3000 \\
\hline 12 & 1 & 9010 & 7.02 & 1.4 & 0.7 & 2.6 & 3000 \\
\hline 13 & 1 & 9010 & 7.02 & 1.6 & 0.8 & 2.6 & 3000 \\
\hline 14 & 3 & 9010 & 7.02 & 1.9 & 0.95 & 2.6 & 3000 \\
\hline
\end{tabular}


Pre-print ver. (Matsuoka, Yageta, Nakamichi, Kasahara, Yajima, Kojima, JOURNAL OF PROPULSION AND POWER Vol. 27, No. 3, May-June 2011)

Table 4 Initial condition of the mechanical model

\begin{tabular}{lcc}
\hline \hline Initial position & $x_{\mathrm{n}}$ & $0.060 \mathrm{~m}$ \\
Position at left wall & $x_{\mathrm{w} 2}$ & $0.060 \mathrm{~m}$ \\
Supply port position & $x_{\mathrm{s}}$ & $0.076 \mathrm{~m}$ \\
Exhaust port position & $x_{\mathrm{e}}$ & $0.076 \mathrm{~m}$ \\
Position at right wall & $x_{\mathrm{w} 1}$ & $0.090 \mathrm{~m}$ \\
Spring natural length & $x_{\mathrm{n}}$ & $0.060 \mathrm{~m}$ \\
Friction coefficient & $\mu$ & $40 \mathrm{Ns} / \mathrm{m}$ \\
Piston cross section & $A$ & $0.00071 \mathrm{~m}^{2}$ \\
Rebound coefficient at right wall & $e_{\mathrm{w} 1}$ & 0.3 \\
Rebound coefficient at left wall & $e_{\mathrm{w} 2}$ & 0.5 \\
Pressure correction coefficient & $\alpha$ & $0.6 \sim 1.0$ \\
\hline \hline
\end{tabular}


Pre-print ver. (Matsuoka, Yageta, Nakamichi, Kasahara, Yajima, Kojima, JOURNAL OF PROPULSION AND POWER Vol. 27, No. 3, May-June 2011)

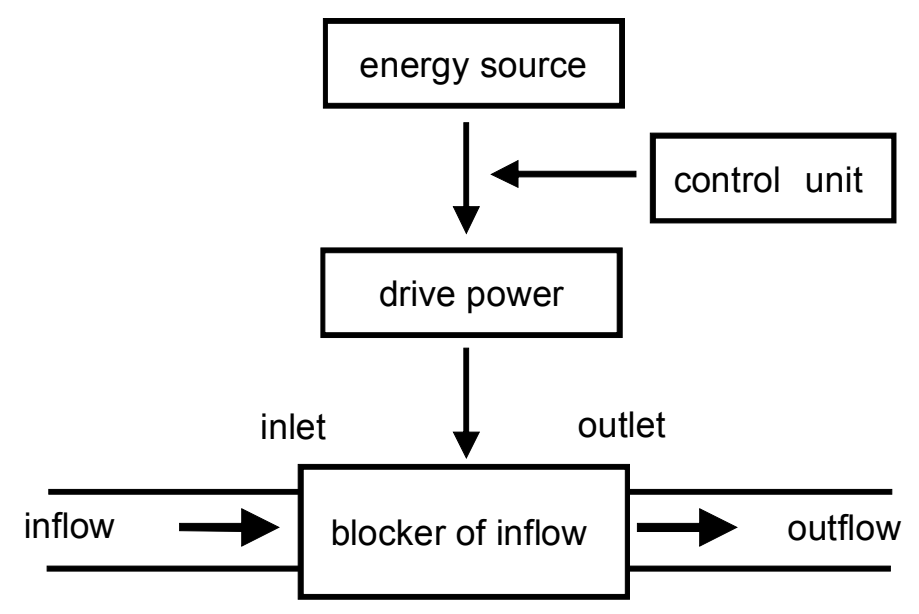

Fig. 1 Schematic diagram of a valve system 
Pre-print ver. (Matsuoka, Yageta, Nakamichi, Kasahara, Yajima, Kojima, JOURNAL OF PROPULSION AND POWER Vol. 27, No. 3, May-June 2011)

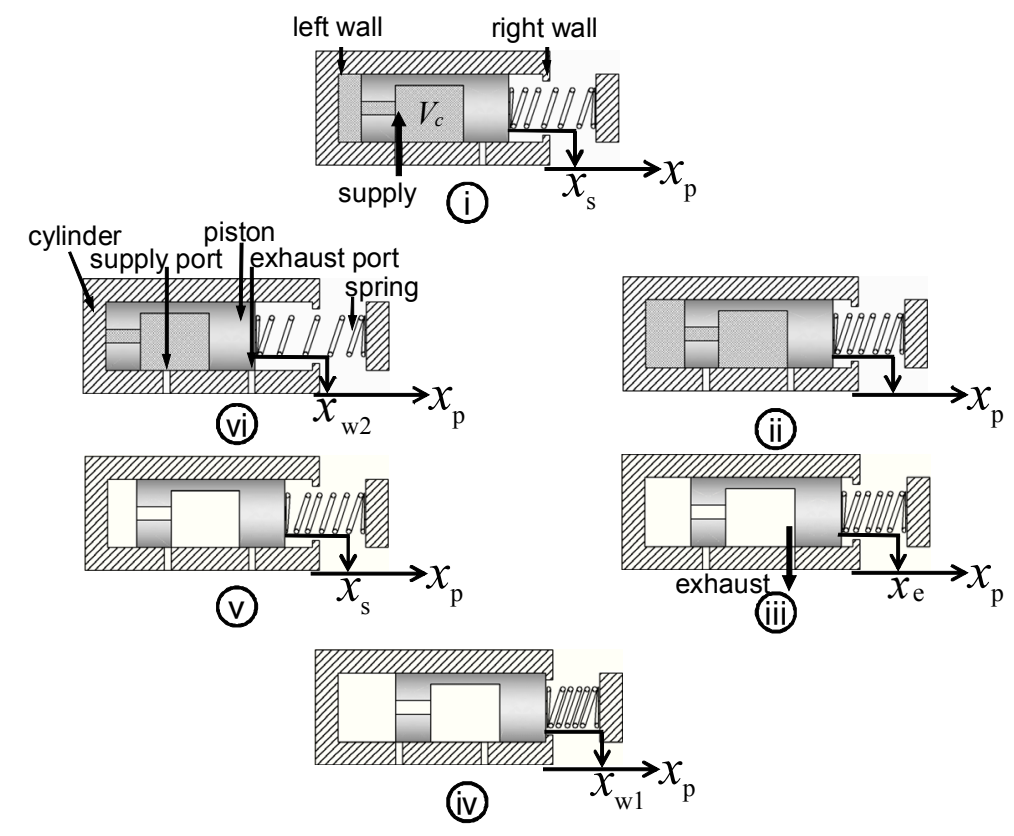

Fig. 2 Operation conceptual diagram of an inflow-driven valve 
Pre-print ver. (Matsuoka, Yageta, Nakamichi, Kasahara, Yajima, Kojima, JOURNAL OF PROPULSION AND POWER Vol. 27, No. 3, May-June 2011)

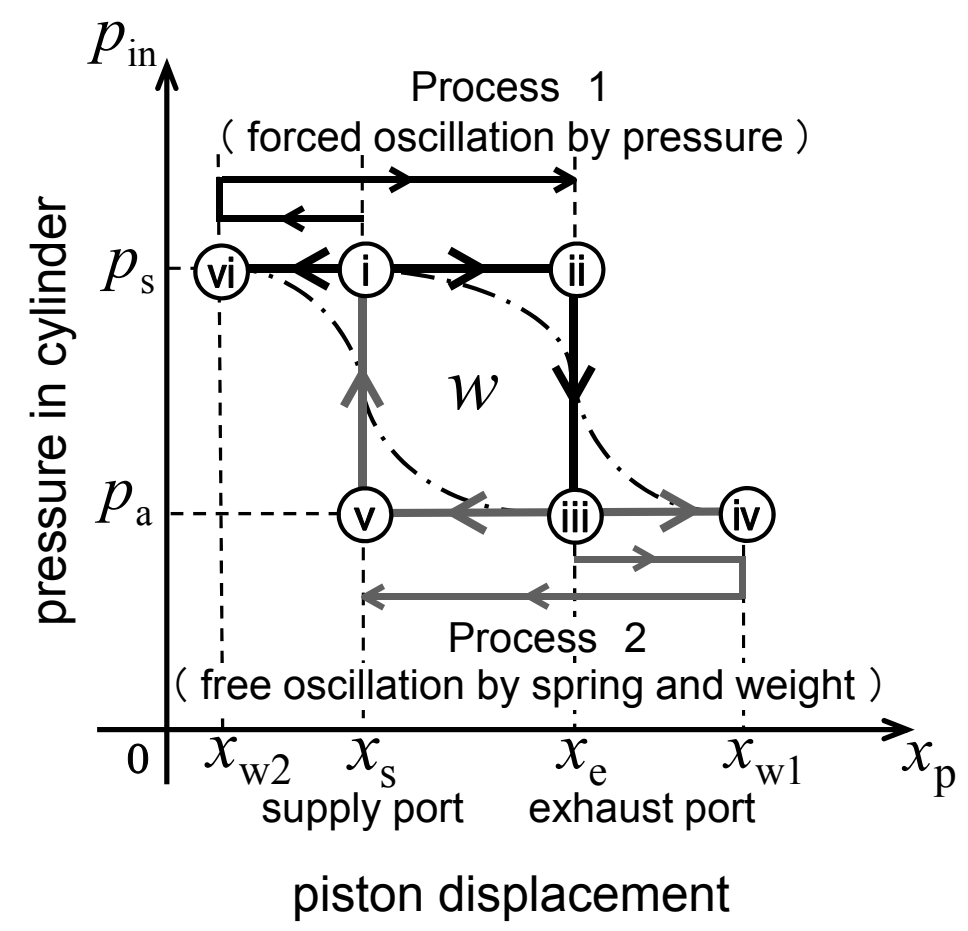

Fig. 3 Ideal and actual operation cycle of an inflow-driven valve 
Pre-print ver. (Matsuoka, Yageta, Nakamichi, Kasahara, Yajima, Kojima, JOURNAL OF PROPULSION AND POWER Vol. 27, No. 3, May-June 2011)

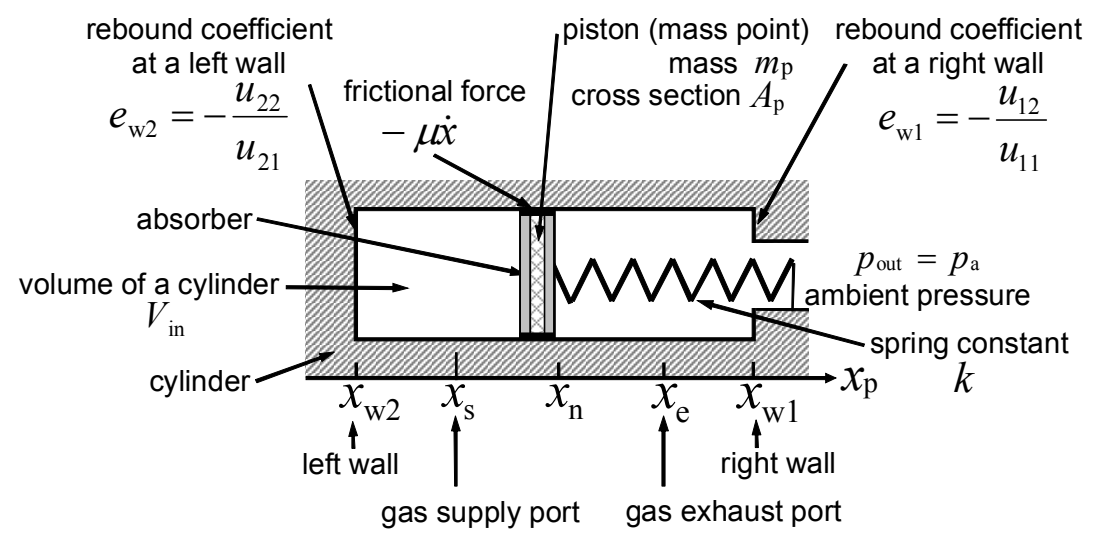

Fig. 4 Dynamic model of an inflow-driven valve 
Pre-print ver. (Matsuoka, Yageta, Nakamichi, Kasahara, Yajima, Kojima, JOURNAL OF PROPULSION AND POWER Vol. 27 , No. 3, May-June 2011)

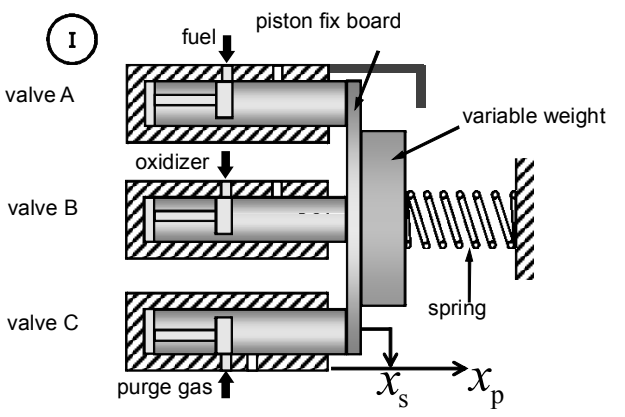

(v)

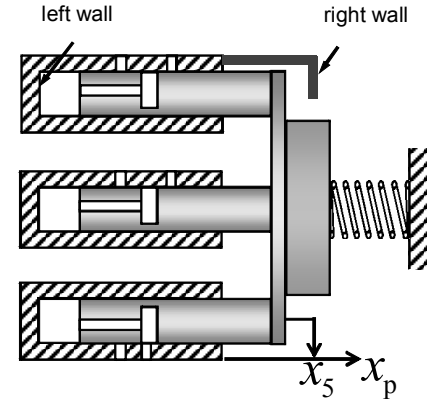

(v)

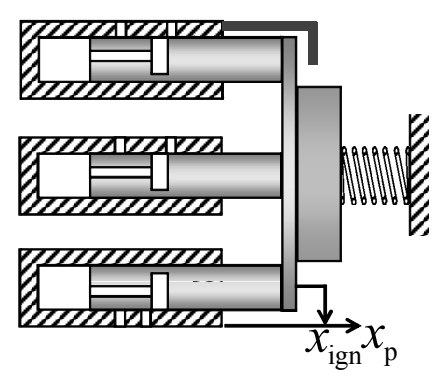

(II)

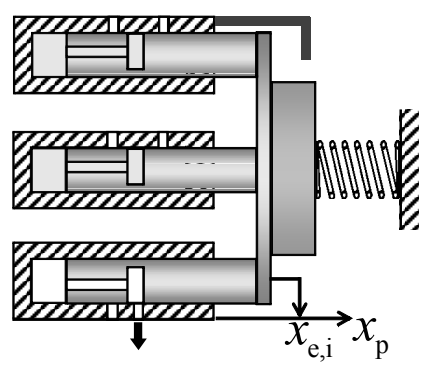

(II)

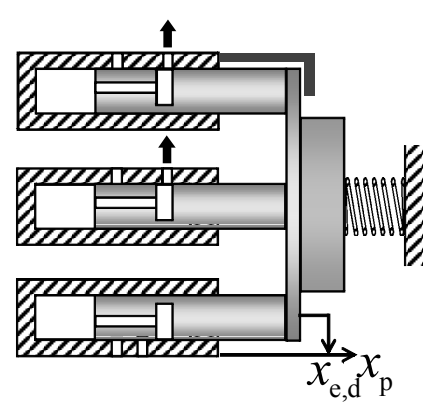

Fig. 5 Operation conceptual diagram of a three-piston inflow-driven valve 
Pre-print ver. (Matsuoka, Yageta, Nakamichi, Kasahara, Yajima, Kojima, JOURNAL OF PROPULSION AND POWER Vol. 27, No. 3, May-June 2011)

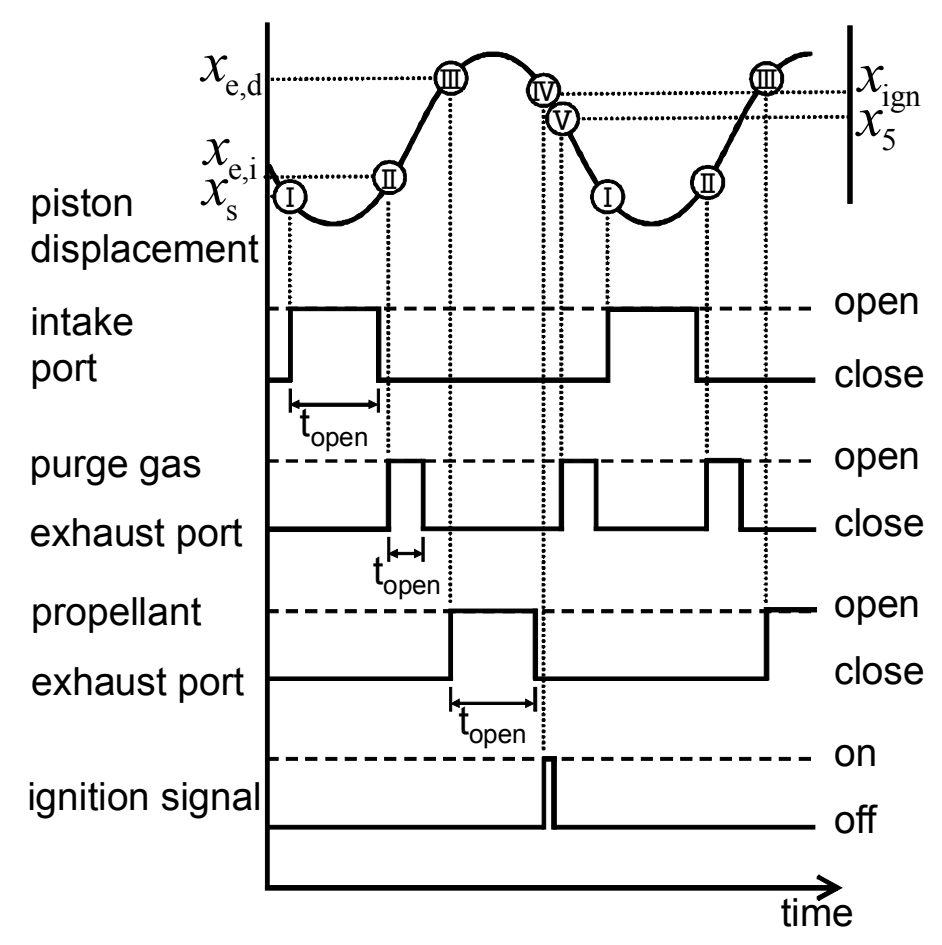

Fig. 6 Piston displacement and operation sequence 
Pre-print ver. (Matsuoka, Yageta, Nakamichi, Kasahara, Yajima, Kojima, JOURNAL OF PROPULSION AND POWER Vol. 27, No. 3, May-June 2011)

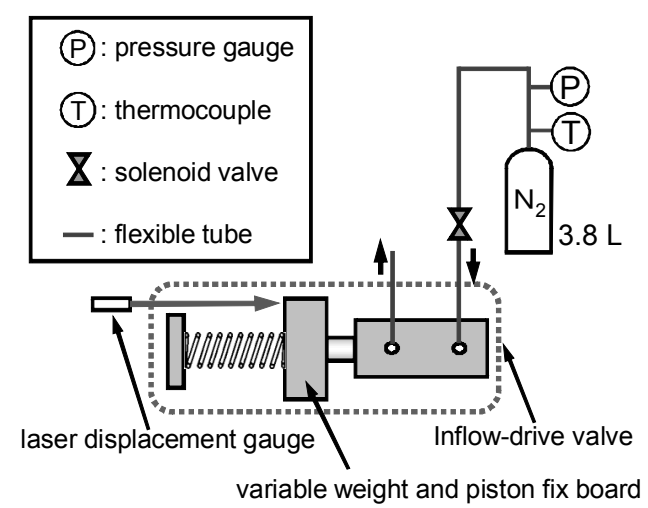

Fig. 7 Schematic diagram of mass flow rate measurement 
Pre-print ver. (Matsuoka, Yageta, Nakamichi, Kasahara, Yajima, Kojima, JOURNAL OF PROPULSION AND POWER Vol. 27, No. 3, May-June 2011)

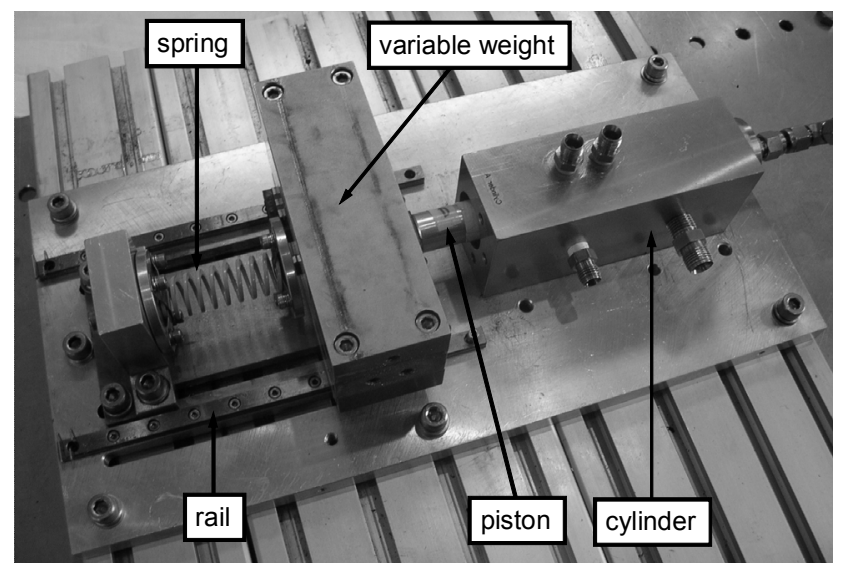

Fig. 8 Photograph of a single piston inflow-driven valve 
Pre-print ver. (Matsuoka, Yageta, Nakamichi, Kasahara, Yajima, Kojima, JOURNAL OF PROPULSION AND POWER Vol. 27, No. 3, May-June 2011)

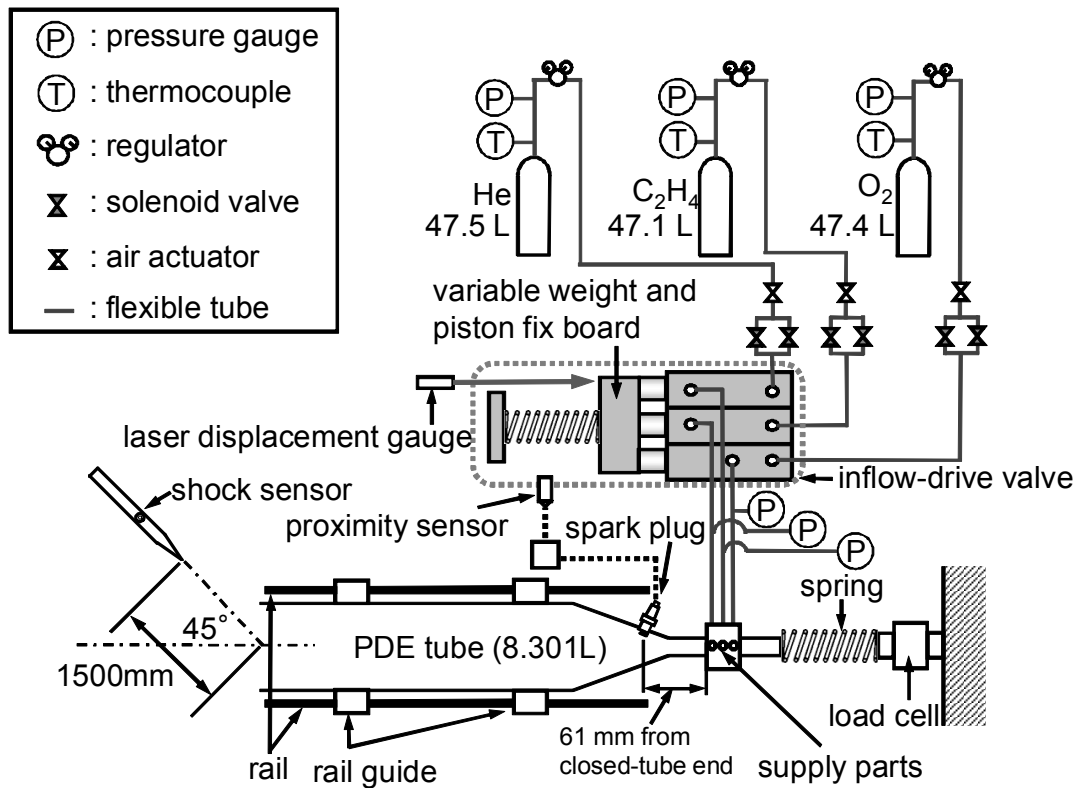

Fig. 9 Schematic diagram of thrust measurement experiment apparatus of a PDRE system 
Pre-print ver. (Matsuoka, Yageta, Nakamichi, Kasahara, Yajima, Kojima, JOURNAL OF PROPULSION AND POWER Vol. 27, No. 3, May-June 2011)

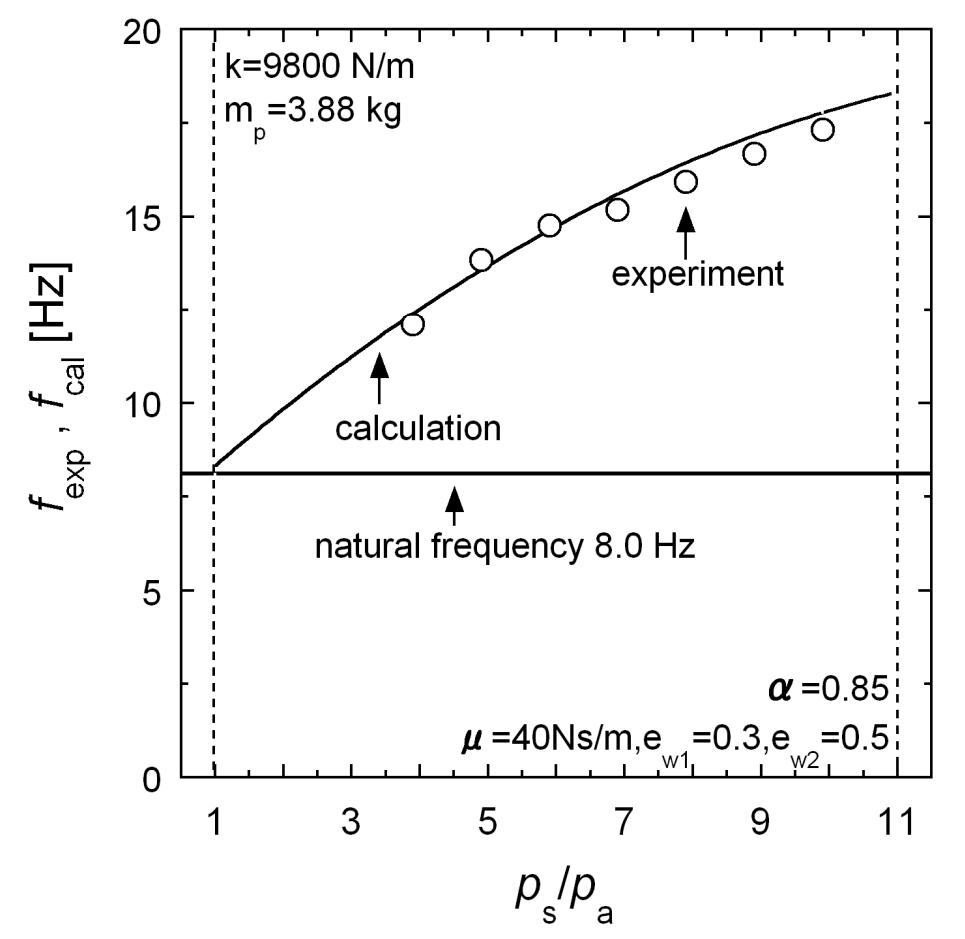

Fig. 10 Operation frequency versus supply pressure

$$
\left(k=9800 \mathrm{~N} / \mathrm{m}, \quad m_{\mathrm{p}}=\mathbf{3 . 8 8} \mathbf{~ k g}\right)
$$


Pre-print ver. (Matsuoka, Yageta, Nakamichi, Kasahara, Yajima, Kojima, JOURNAL OF PROPULSION AND POWER Vol. 27, No. 3, May-June 2011)

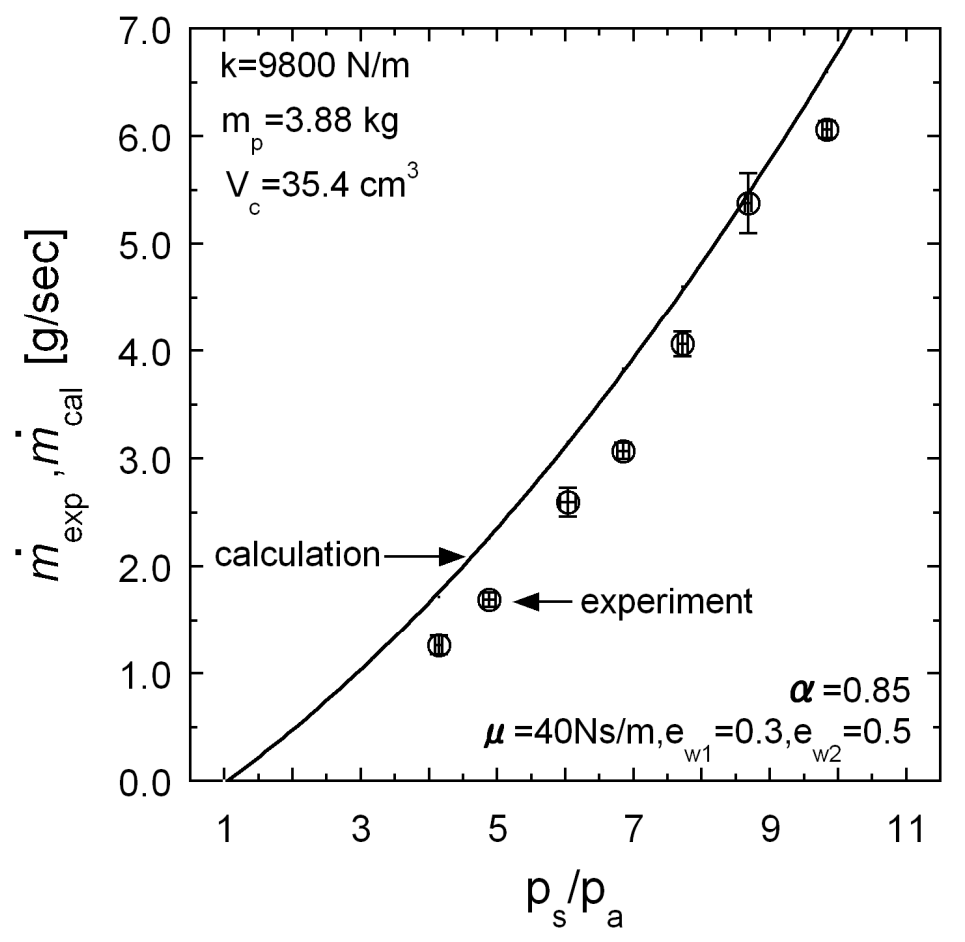

Fig. 11 Mass flow rate versus supply pressure

$\left(k=9800 \mathrm{~N} / \mathbf{m}, \quad m_{\mathrm{p}}=\mathbf{3 . 8 8} \mathbf{~ k g}\right)$ 
Pre-print ver. (Matsuoka, Yageta, Nakamichi, Kasahara, Yajima, Kojima, JOURNAL OF PROPULSION AND POWER Vol. 27, No. 3, May-June 2011)

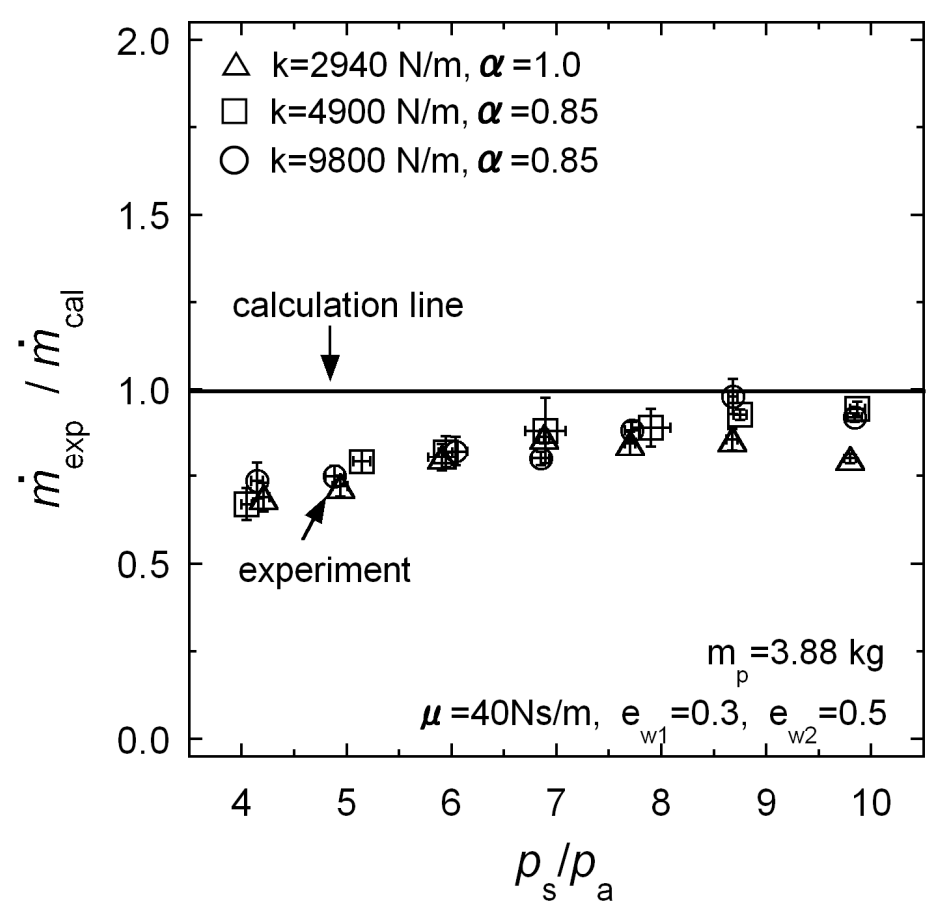

Fig. 12 Mass flow ratio versus supply pressure

$$
\left(m_{\mathrm{p}}=\mathbf{3 . 8 8} \mathbf{~ k g}\right)
$$


Pre-print ver. (Matsuoka, Yageta, Nakamichi, Kasahara, Yajima, Kojima, JOURNAL OF PROPULSION AND POWER Vol. 27, No. 3, May-June 2011)

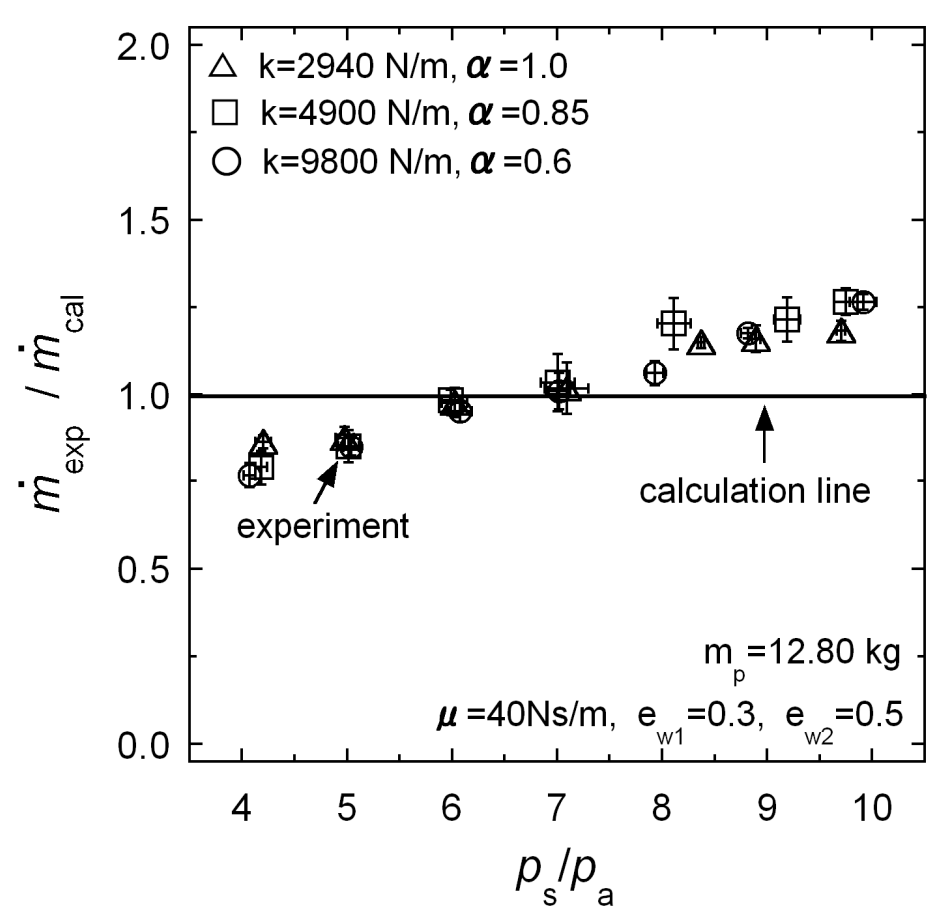

Fig. 13 Mass flow ratio versus supply pressure

$$
\left(m_{\mathrm{p}}=\mathbf{1 2 . 8 0} \mathbf{~ k g}\right)
$$


Pre-print ver. (Matsuoka, Yageta, Nakamichi, Kasahara, Yajima, Kojima, JOURNAL OF PROPULSION AND POWER Vol. 27 , No. 3, May-June 2011)

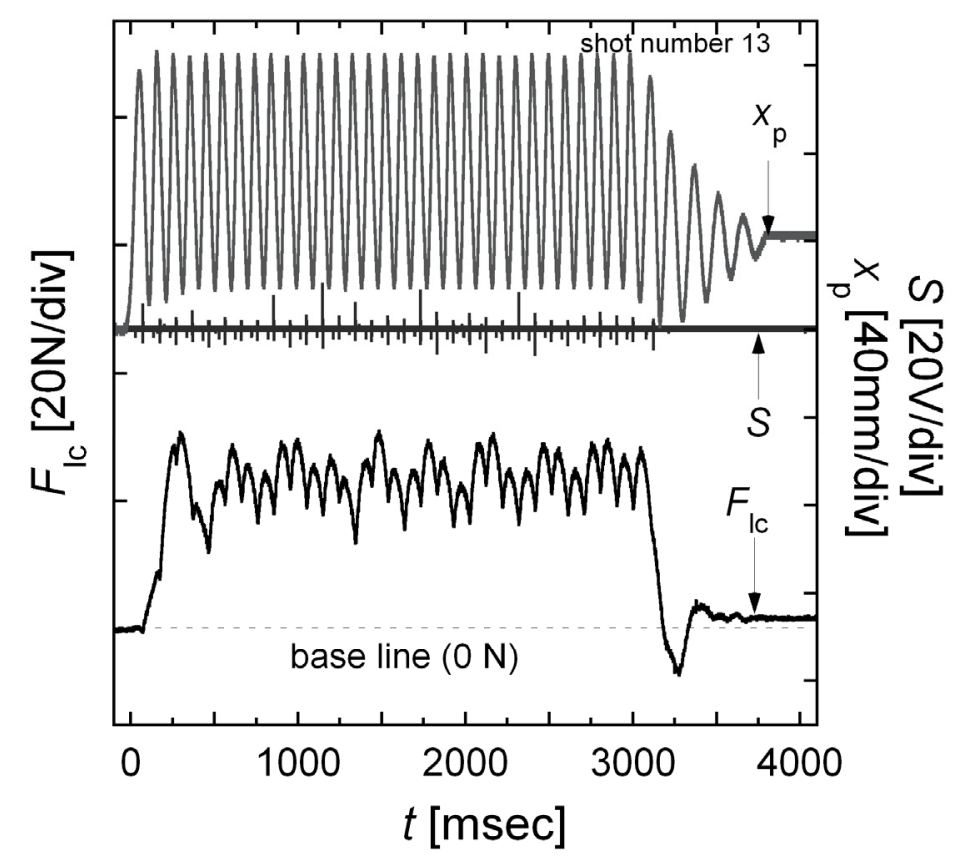

Fig. 14 Time history of thrust measurement experiment

(shot 13) 
Pre-print ver. (Matsuoka, Yageta, Nakamichi, Kasahara, Yajima, Kojima, JOURNAL OF PROPULSION AND POWER Vol. 27, No. 3, May-June 2011)

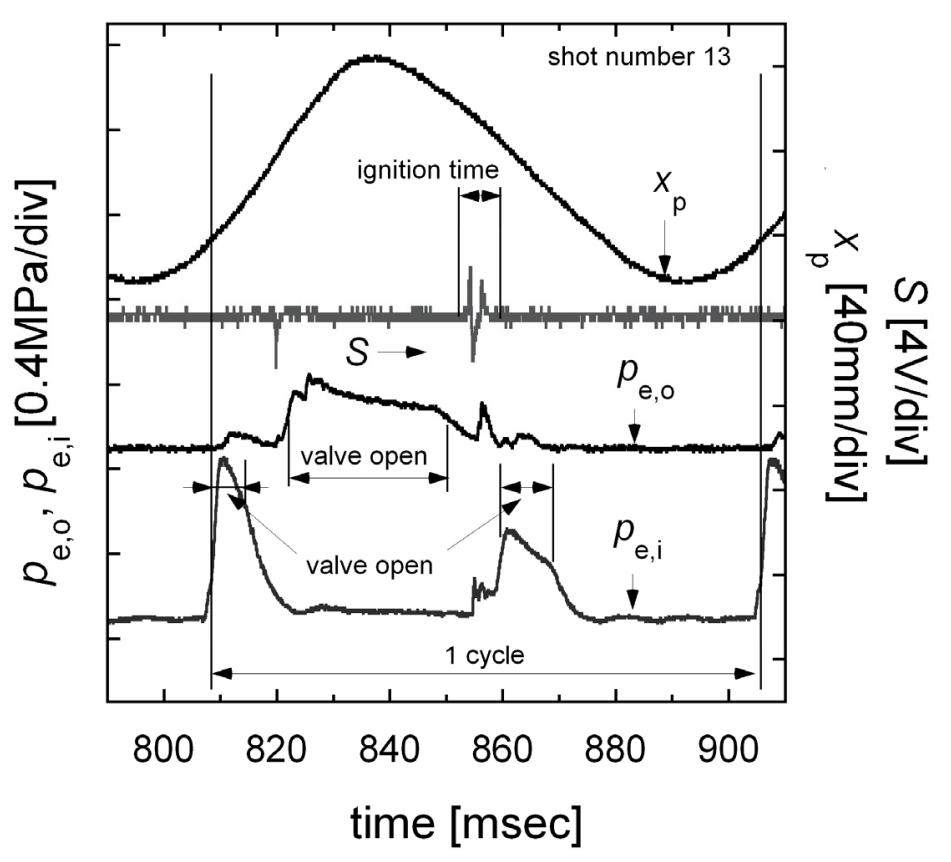

Fig. 15 One cycle of the thrust measurement experiment

(shot 13) 
Pre-print ver. (Matsuoka, Yageta, Nakamichi, Kasahara, Yajima, Kojima, JOURNAL OF PROPULSION AND POWER Vol. 27, No. 3, May-June 2011)

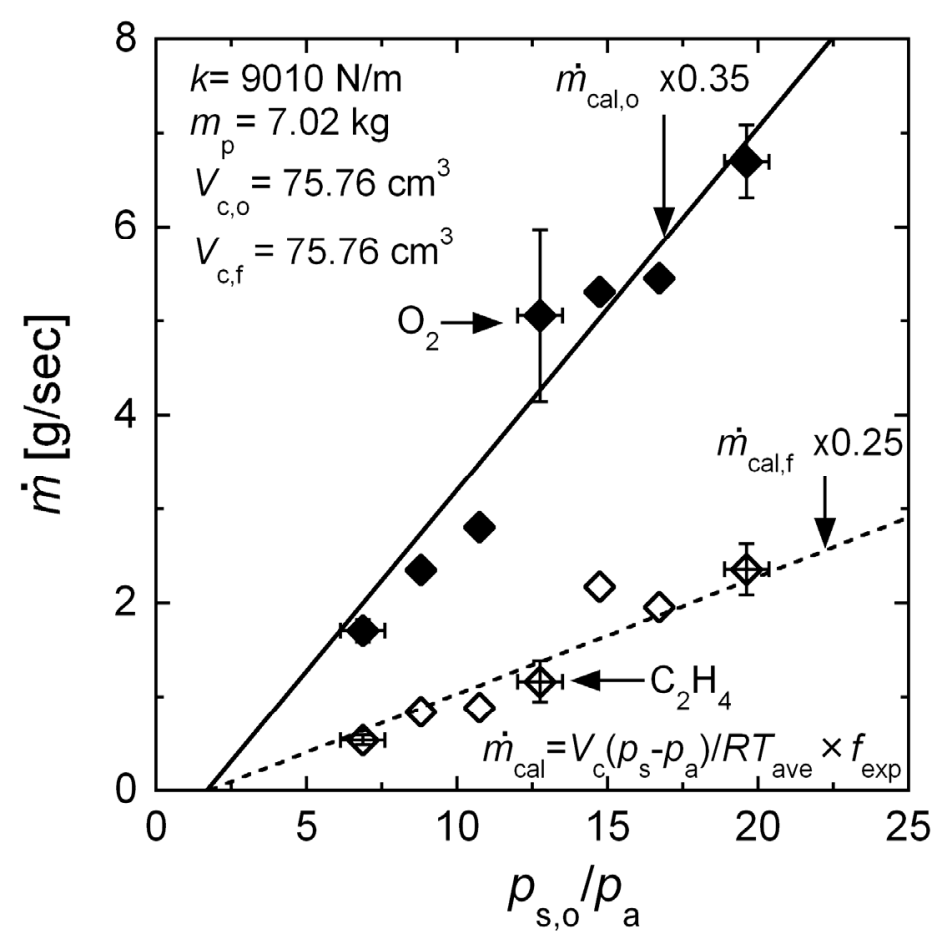

Fig. 16 Mass flow rate versus oxygen supply pressure

$$
\left(k=9010 \mathrm{~N} / \mathrm{m}, \quad m_{\mathrm{p}}=7.02 \mathrm{~kg}\right)
$$


Pre-print ver. (Matsuoka, Yageta, Nakamichi, Kasahara, Yajima, Kojima, JOURNAL OF PROPULSION AND POWER Vol. 27, No. 3, May-June 2011)

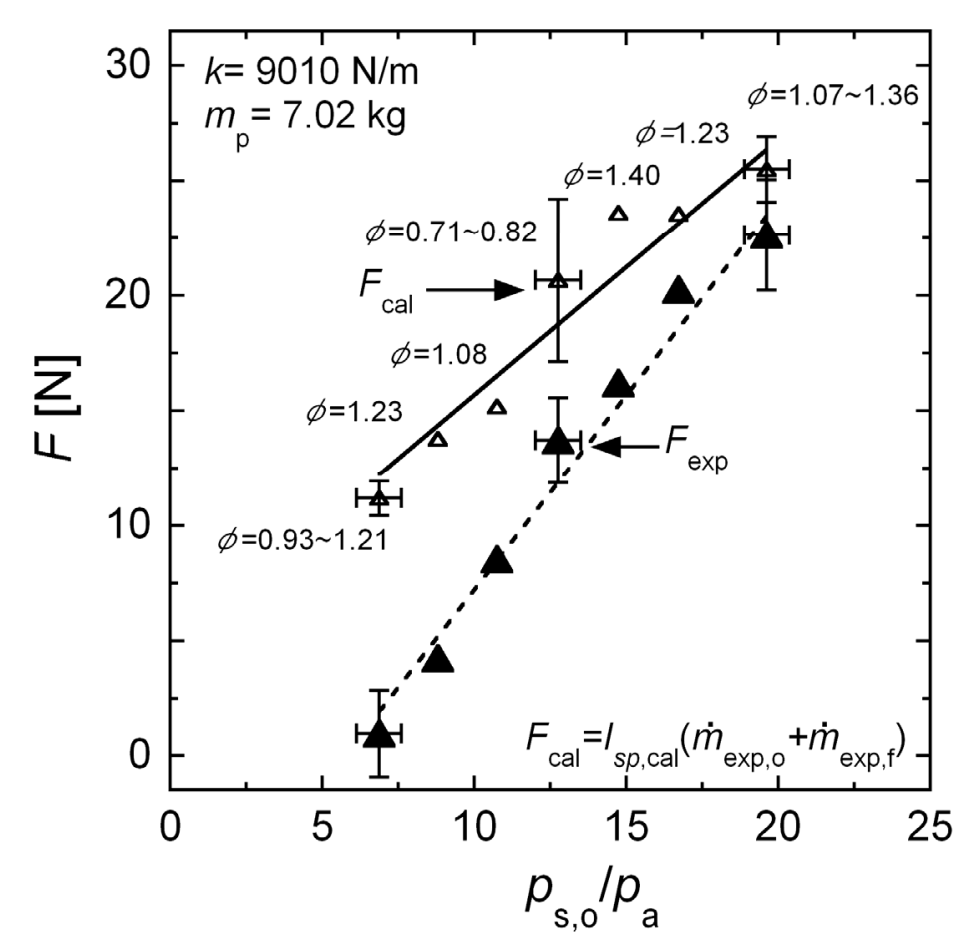

Fig. 17 Thrust versus oxygen supply pressure

$$
\left(k=9010 \mathrm{~N} / \mathrm{m}, \quad m_{\mathrm{p}}=7.02 \mathrm{~kg}\right)
$$


Pre-print ver. (Matsuoka, Yageta, Nakamichi, Kasahara, Yajima, Kojima, JOURNAL OF PROPULSION AND POWER Vol. 27, No. 3, May-June 2011)

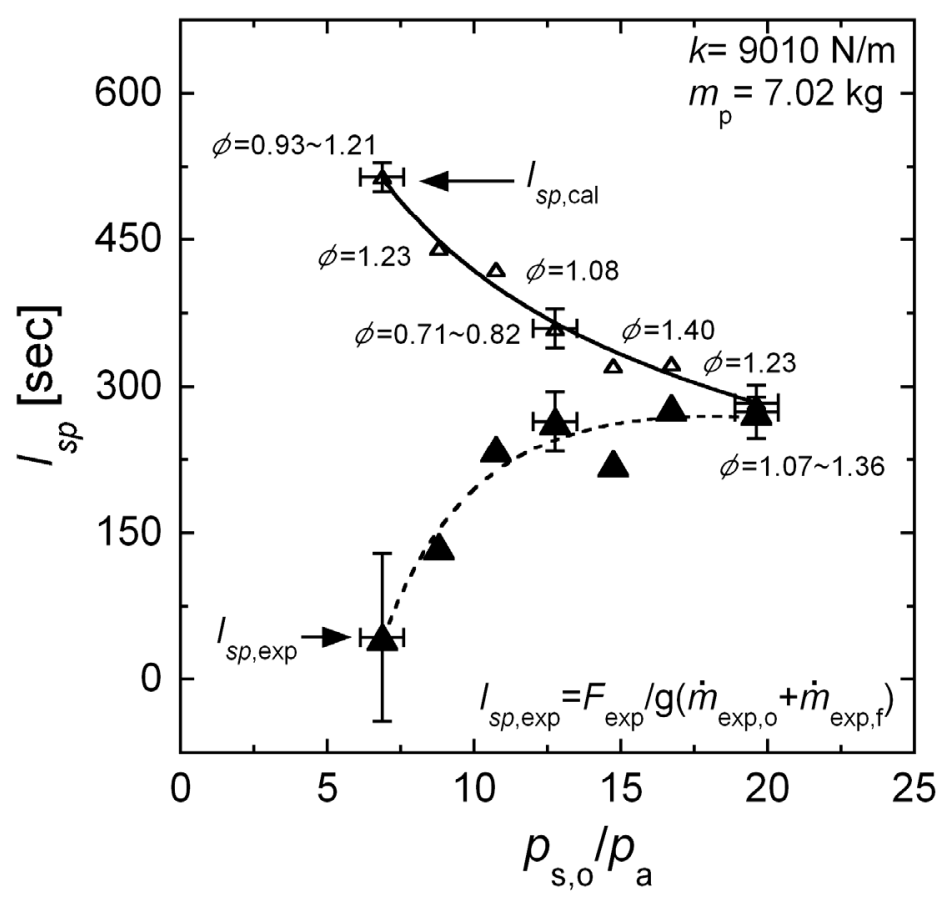

Fig. 18 Specific impulse versus oxygen supply pressure

$$
\left(k=9010 \mathrm{~N} / \mathrm{m}, \quad m_{\mathrm{p}}=7.02 \mathrm{~kg}\right)
$$


Pre-print ver. (Matsuoka, Yageta, Nakamichi, Kasahara, Yajima, Kojima, JOURNAL OF PROPULSION AND POWER Vol. 27, No. 3, May-June 2011)

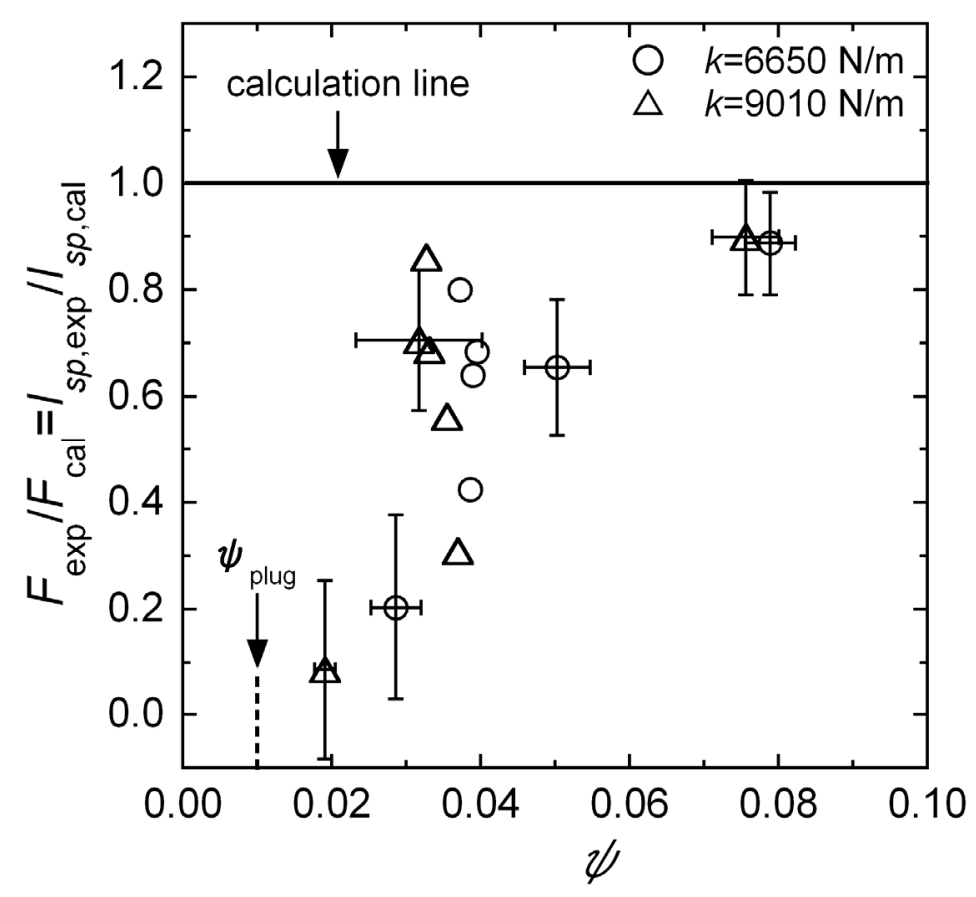

Fig. 19 Thrust ratio versus propellant fill fraction 